\title{
Acción colectiva y resistencia: asalariadas agrícolas en Chile frente a la precarización laboral
}

\section{Collective action and resistance: agricultural women workers in Chile in the face of labor precarization}

\author{
Ximena Valdés S. - Carmen Gloria Godoy R.* - Angie Mendoza A.***
}

\begin{abstract}
Resumen: Este artículo da cuenta de las acciones colectivas, entendidas como nuevas formas de resistencia, que ha desplegado la Asociación Nacional de Mujeres Rurales e Indígenas (ANAMURI), una organización social de mujeres rurales y asalariadas del agro que surge en Chile durante la década de 1990. Basado en fuentes escritas, orales, documentos y observación directa en reuniones y congresos de la organización, el artículo aborda la variada gama de estrategias para hacer frente a la precarización laboral de las "temporeras" que trabajan en agro-exportación.
\end{abstract}

Palabras clave: asalariadas agrícolas, precarización laboral, acción colectiva, resistencia

\begin{abstract}
This article gives an account of the collective actions understood as new forms of resistance that have been developed by the National Association of Rural and Indigenous Women (ANAMURI) a social organization of rural women and wage workers of the agricultural sector that emerged in Chile in the 1990s. From written and oral sources, documents and direct observations at meetings and congresses of the organization, this paper addresses the wide range of strategies to face the precarious working conditions of "seasonal workers" working in agro-export sector.
\end{abstract}

Keywords: agricultural women workers, precarious employment, collective action, resistance

Recibido: 30 enero 2017

Aceptado: 3 abril 2017

\footnotetext{
* Chilena, autora principal, Geógrafa, Doctora en Estudios Americanos, Mención Historia Económica y Social, USACH/IDEA, Santiago, Chile; DEA Tercer Mundo, Magíster, Licenciatura Geografía, Universidad París VII, París, Francia. Directora CEDEM; docente Escuela de Geografía, Universidad Academia de Humanismo Cristiano. Responsable Proyecto FONDECYT 1150646 "Trayectoria e incidencia de la organización social y acción colectiva de las mujeres rurales en Chile" (marzo 2015-marzo 2018). ximena.valdes@cedem.cl

** Chilena. Coautora. Antropóloga, Doctora en Estudios Latinoamericanos, Universidad de Chile; Magíster en Estudios de Género y Cultura, Universidad de Chile. Coinvestigadora, Proyecto FONDECYT 1150646. cggodoy82@gmail.com

Chilena. Coautora. Trabajadora Social. Magister Sociología, Universidad de Chile, Coinvestigadora, Proyecto FONDECYT 1150646. amendozaar@gmail.com.
} 


\section{Introducción}

«Hablar es un movimiento en sí mismo y "movimiento" conlleva dos sentidos básicos: movilidad corporal y organización política» Judith Butler, Nosotros el pueblo. Apuntes sobre la libertad de reunión, LOM, 2014

La salarización temporal en la agricultura de exportación es un fenómeno con alcance latinoamericano que ha contribuido a producir cambios en las relaciones sociales de género en un escenario de feminización del mercado de trabajo ${ }^{1}$ que ha ido de la mano con la flexibilización del empleo. Tal como en otros países, en Chile, los principales sostenedores económicos de las familias, los trabajadores hombres, perdieron la estabilidad laboral lograda bajo sistemas de protección social desmantelados tras la reestructuración macro económica iniciada en la década de los ochenta, mientras las mujeres se incorporaron masivamente al mercado de trabajo en un escenario de precarización laboral que se instaló bajo las economías neoliberales globalizadas en las últimas décadas del siglo $\mathrm{XX}^{2}$.

Estos cambios han dejado huellas en la organización social de los trabajadores, abriendo paso a la conformación de nuevos actores sociales que pugnan por mitigar las precarias condiciones de trabajo que enfrentan.

Siguiendo las reflexiones de Luc Boltanski ${ }^{3}$, las formas de protesta analizadas desde distintas disciplinas, principalmente la historia social y la sociología, reposan en la distinción entre acción individual y acción colectiva. Esta última incluye grupos sociales que manifiestan algún grado de identificación o identidad que se refuerza en la denuncia frente a algún problema común. En este campo se inscribe el análisis del presente texto que aborda las estrategias de denuncia de las precarias condiciones de trabajo en la agricultura de exportación llevada adelante desde hace algunas décadas por la Asociación Nacional de Mujeres Rurales e Indígenas -ANAMURI-. El marco conceptual de este análisis se desarrolla una vez descritos los hitos y formas de despliegue de la denuncia que nos han llevado a calificarla como acción colectiva o de resistencia de las mujeres frente a la precarización del empleo lo que distintos autores definen como manifestaciones actuales de los movimientos

\footnotetext{
${ }^{1}$ Ximena Valdés, "Feminización del mercado de trabajo agrícola en Chile Central”, en Mundo de mujer. Continuidad y cambio, Santiago, CEM, 1988, 387-430.

${ }^{2}$ Marta Radonich y Norma Steimbreger (comps.), Reestructuraciones sociales en cadenas agroalimentarias, Buenos Aires, La Colmena, 2007.

${ }^{3}$ Luc Boltanski,Yan Derré, Marie-Ange Schiltz. "La dennonciation”, en Actes de la récherche en sciences sociales, Vol, 51, mars 1984, 3-40
} 
populares ${ }^{4}$ en Latinoamérica a diferencia de las definiciones dadas a los nuevos movimientos sociales del capitalismo tardío por autores como Touraine ${ }^{5}$.

\subsection{Propósito, supuestos y fuentes}

En este contexto, la interrogante que guía esta investigación es la siguiente: ¿Cómo las temporeras han hecho frente al trabajo precario en un escenario de indefensión de los/las trabajadores/as agrícolas expresado en la des-sindicalización tras la derrota que sufrió el campesinado con la Contrarreforma agraria? ${ }^{6}$. El artículo entrega antecedentes sobre la organización social durante la Reforma Agraria y analiza las estrategias de acción colectiva desplegadas por la Asociación Nacional de Mujeres Rurales e Indígenas (ANAMURI). Para ello reconstruye su trayectoria organizativa, enraizada en la experiencia de algunas de sus dirigentas en el movimiento campesino y la militancia de izquierda que acompañó a la Reforma Agraria, y evalúa la influencia de las organizaciones de mujeres, feministas urbanas y latinoamericanas en general, durante la dictadura y postdictadura en Chile, indagando en el nuevo contexto de discursos y políticas públicas que revalorizan el papel de las mujeres en la sociedad. Finalmente se deja abierto el debate sobre la forma que asumen las acciones colectivas $-\mathrm{o}$ de resistencia- como respuestas contrahegemónicas que se incuban en la sociedad contemporánea frente al neoliberalismo, la globalización y sus consecuencias en las trabajadoras del agro.

Los datos se han obtenido de fuentes secundarias y documentales, de publicaciones y de las páginas web de ANAMURI $^{7}$ y otras organizaciones, de instituciones públicas (Instituto Nacional de Estadística, INE; Instituto de Desarrollo Agropecuario, INDAP; Dirección del Trabajo, Ministerio del Trabajo), de fuentes primarias (entrevistas individuales y grupales a dirigentas y socias de ANAMURI, dirigentes sindicales, profesionales de organizaciones no gubernamentales, que han estado cerca de su desarrollo y acompañándolas en distintas actividades, y de parlamentarias feministas. A ello se agrega la observación participante en encuentros, reuniones y congresos organizados por ellas entre 1998 y 2016, y por las mujeres de los Departamentos Femeninos de las Confederaciones Sindicales Campesinas entre 1980 y 1998, antes de la formación de ANAMURI.

El recurso a fuentes orales, en este caso entrevistas, como lo han destacado historiadoras como Michelle Perrot ${ }^{8}$ es particularmente importante cuando de mujeres se trata en la medida que la historiografía y las ciencias sociales poco interés han manifestado hasta hace poco tiempo por incorporar al género como categoría de análisis e incorporar a las mujeres

\footnotetext{
${ }^{4}$ David Slater, David, Nuevos movimientos sociales y el Estado en Latinoamérica, Ámsterdam, CEDLA, 1985; Joe Foweraker y Ann L. Craig (eds.), Popular Movements and Political Change in Mexico, Londres y Boulder, Lynne Rienner, 1990.

${ }^{5}$ Alain Touraine, El retorno del actor, Buenos Aires, Editorial Universitaria, 1988.

${ }^{6}$ José Bengoa, Reforma agraria o revuelta campesina. Homenaje a los campesinos desaparecidos, Santiago, LOM, 2016.

${ }^{7}$ Página web: <www.anamuri.cl>.

${ }^{8}$ Michelle Perrot, Haciendo Historia en Género e Historia, comp. Carmen Ramos, México, Universidad Autónoma Metropolitana. 1992.
} 
en los estudios de estas disciplinas. De otro lado, para la Historia del Presente el material recogido a través de entrevistas o testimonios orales constituyen fuentes privilegiadas de conocimiento de fenómenos contemporáneos como el aquí estudiado 9 .

Como hipótesis nos planteamos que en un contexto de discursos públicos emancipatorios que promueven la igualdad de género y la incorporación de las mujeres al mercado laboral, un número muy significativo de mujeres han engrosado el mercado de trabajo en la agricultura de exportación. No obstante, en este tipo de empleo las temporeras enfrentan agudos grados de explotación en una situación de generalizada indefensión en el marco de la dessindicalización de los trabajadores agrícolas. Bajo este escenario, sin embargo, las mujeres se organizan creando distintas estrategias de resistencia a la precarización laboral. Entre ellas, acciones colectivas frente a los padecimientos laborales y la falta de derechos en el trabajo. Construyendo demandas se transforman en interlocutoras frente al Estado, otros agentes y actores tras la gran derrota que sufrieron las organizaciones sindicales de campesinos y trabajadores agrícolas con el golpe de Estado de 1973 y la dictadura militar. Al mismo tiempo, la organización genera un fuerte vínculo identitario entre quienes forman parte de esta Asociación que se proyecta a nivel local, nacional e internacional. Ciertas preguntas se deducen de este supuesto: ¿qué tipo de actor social emerge de una economía política que excluye a las trabajadoras de derechos laborales pero que al mismo tiempo esta exclusión se ve cruzada por políticas de reconocimiento en tanto que mujeres?, ¿qué tipo de acción colectiva han desplegado las mujeres que trabajan en la agricultura de exportación frente a la precarización laboral?, ¿de qué manera el referente 'mujer' opera como elemento articulador de las demandas de las mujeres trabajadoras?

El análisis se organiza en tres partes. Se plantean problemas inherentes a esta categoría laboral, se describe el tipo de organización social existente durante la Reforma Agraria y la suerte que corrió el sindicalismo bajo el neoliberalismo con el fin de otorgar un marco histórico al surgimiento y la trayectoria de ANAMURI. En segundo lugar se describen las estrategias llevadas adelante por ANAMURI. Por último, se problematizan e interpretan las acciones colectivas llevadas adelante por esta organización procurando visualizar su incidencia en regímenes neoliberales globalizados altamente hostiles al mundo del trabajo.

\section{Tensiones, paradojas y complejidades}

\subsection{La marca del género, la etnia y la nacionalidad en el empleo temporal}

Los trabajadores agrícolas permanentes, mayoritariamente hombres y chilenos, que laboran en la agroindustria, las plantaciones de frutales y las viñas, son menos que los temporales. En cambio son mayoritarios los hombres y mujeres provenientes de población rural local y de las periferias urbanas, de comunidades campesinas e indígenas, incluyendo a migrantes extranjeros que hacen parte de la categoría laboral de temporeros, jornaleros, boias frias,

\footnotetext{
${ }^{9}$ Julio Arostegui, La Historia del presente ¿Una cuestión de método?, Universidad complutense de Madrid, Dialnet/laHistoriaDelPresente-1036594.pdf
} 
según su nominación en cada país de la región ${ }^{10}$. La movilidad geográfica transforma a una buena parte de esta categoría laboral en "nómades asalariados": conjunto heterogéneo de hombres, mujeres, indígenas, extranjeros, que buscan un mismo fin desplazándose para obtener un salario $^{11}$. Marcadas por el género, la etnia y la nacionalidad, las migraciones laborales permiten alargar el tiempo de asalarización en la medida que, para "hacerse el salario", las temporeras y los temporeros se desplazan entre empresas y valles ${ }^{12}$. Las migraciones internas en los países y las migraciones transfronterizas ${ }^{13}$, al traducirse en circulación estacional de fuerza de trabajo, constituyen "territorios migratorios" que se reactivan en cada temporada agrícola ${ }^{14}$, muchas veces sostenidos en redes de parentesco y de pares creadas en la misma experiencia migratoria. A esta modalidad se suman otras, como el "enganche" de trabajadores por empresas chilenas articuladas a empresas de otros países que cuentan con sistemas de traslado, como se ha evidenciado en la prensa haciendo visible la contratación de temporeros originarios de Nepal, Haití o Paraguay ${ }^{15}$ bajo el argumento empresarial de la escasez de mano de obra ${ }^{16}$.

\footnotetext{
${ }^{10}$ Sara María Lara, "Los territorios migratorios como espacios de integración de las migraciones nacionales e internacionales. Cuatro estudios de caso en México", Política y Sociedad. Monográfico sobre migraciones, trabajo y cadenas globales, 49:1, septiembre, 2012, 89-102; Sara María Lara, "Savoir gérer la distance et la précarité: les salariés agricoles au Mexique”, Migrations Société, 153-154, mayo-agosto, 2014, 197-209; Ximena Valdés, “Trabajo agrícola temporal, familias, géneros”, en Ximena Valdés et al., Trabajos y familias en el neoliberalismo. Hombres y mujeres en faenas de la uva, el salmón y el cobre, Santiago, LOM, 2014, 2197; Ximena Valdés, "Conclusiones", en FAO / CEPAL / OIT, Empleo y condiciones de trabajo de mujeres temporeras agrícolas, Santiago, tomo I, 223-247, tomo II, 269-300, 2012.

${ }^{11}$ Sobre migraciones mapuches a la zona central y cosecha de cerezas véase Paz Neira, Trabajadores temporeros mapuche en la fruticultura: el caso de la Comunidad Juan José Ayenao, Tesis de Magíster, Santiago, Universidad Academia de Humanismo Cristiano, 2012; sobre migraciones de peruanos de ambos sexos a las temporadas de la uva en Copiapó: Angie Mendoza, Incidencia del trabajo de temporada en familias migrantes nacionales y extranjeras. El Valle de Copiapó, Tesis de Magister, Santiago, Facultad de Ciencias Sociales, Escuela de Post-Grado, Universidad de Chile, 2011 (ambas disponibles en Internet: $<$ www.generohistoriaruralidad.cl>).

12 Valdés, op. cit., 2014.

${ }^{13}$ Sara María Lara y Hubert de Grammont, "Los efectos de las migraciones rurales internas en la conformación de los grupos domésticos", en Mónica Bendini, Josefa Salete, Miguel Murmis y Pedro Tsakoumagkos (comps.), El campo en la sociología actual. Una perspectiva latinoamericana, Buenos Aires, La Colmena, 2003, 213-236; Andrés Pedreño, "La condición inmigrante del trabajo en las agriculturas globalizadas”, en Sara María Lara (comp.), Los “encadenamientos migratorios” en espacios de agricultura intensiva, México, El Colegio Mexiquense / Miguel Ángel Porrúa, 2011, 5-15.

${ }^{14}$ Sobre este concepto véase Alain Tarrius, "Pobres en migración, globalización de las economías y debilitamiento de los modelos integradores en el transnacionalismo migratorio en Europa Meridional", Empiria, UNED, Revista de Metodología en Ciencias Sociales, 19, enero-junio, 2010, 133-156. El carácter migratorio del trabajo agrícola temporal en América Latina está documentado en Sara María Lara, "Movilidad y migración de familias jornaleras. Una mirada a través de genealogías", Empiria, UNED, Revista de Metodología en Ciencias Sociales, 19, enero-junio, 2010, 183-201; Valdés, op. cit., 2014.

${ }^{15}$ The Clinic, "Los temporeros de Nepal que trabajan en Buin", Santiago, 18 diciembre 2016; Biobío Chile, "Así vivían decenas de haitianos ilegales descubiertos en Longaví", Santiago, 23 noviembre 2016, entre otras.

${ }^{16}$ Gustavo Anríquez et al., "Evidencia y desafíos para el empleo estacional en la fruticultura en Chile", Temas de la Agenda Pública, 11:85, Santiago, Facultad de Agronomía e Ingeniería Forestal, Pontificia Universidad Católica de Chile, enero, 2016, disponible en Internet: 〈www.politicaspublicas.uc.cl>.
} 
La feminización de las labores en la agricultura de exportación comenzó a conocerse en la década de 1970 en el estado de Sonora, México, donde las mujeres se empleaban en el cultivo de frutillas para el mercado norteamericano ${ }^{17}$. Hallazgos posteriores permitieron conocer las características del empleo que ofrecen las agriculturas latinoamericanas caracterizadas por una generalizada precariedad ${ }^{18}$. La feminización de esta categoría laboral no ha hecho más que intensificar, sin modificaciones significativas las condiciones laborales precarias, como lo han evidenciado diversos estudios realizados en países latinoamericanos y caribeños ${ }^{19}$ y los numerosos estudios sobre la incorporación de las mujeres al trabajo agrícola temporal realizados desde los años ochenta en adelante ${ }^{20}$. Los "territorios migratorios" de asalariadas de temporada hoy se extienden en latitud desde Neuquén, Alto Valle del Río Negro (Argentina) hasta el norte mexicano y Baja California ${ }^{21}$.

Por último, el empleo precario de los temporeros, especialmente de las mujeres, suele acompañarse de programas estatales dirigidos a la mitigación de la pobreza y, en algunos casos, por seguros de desempleo ${ }^{22}$. Las condiciones laborales y las inseguridades que le están asociadas son las que han llevado a incluir a este sector dentro de la categoría "precariado" por su creciente exposición a la vulnerabilidad social y a la desafiliación ${ }^{23}$. Por otro lado, este mercado laboral temporal incluye permanentes reacomodos en la organización del trabajo que tienden a intensificar su precarización (trabajo a destajo, pago por "pieza", por tarea), lo que se traduce en largas jornadas laborales, como ha sido documentado en el caso chileno ${ }^{24}$,

${ }^{17}$ Ernest Feder, El imperialismo fresa. Un estudio sobre los mecanismos de dependencia de la agricultura mexicana, México, Editorial Campesina, 1977.

${ }^{18}$ Sobre los estudios, debates y conceptos sobre precariedad, precarización y precariado cfr. Robert Castel, La montée des incertitudes, París, Seuil, 2009; Robert Castel, La metamorfosis de la cuestión social. Una crónica del salariado, Buenos Aires, Paidós, 1997; Robert Castel, La inseguridad social. ¿Qué es estar protegido?, Buenos Aires, Manantial, 2004; Robert Castel, Gabriel Kessler, Denis Merklen y Numa Mrard, Individuación, precariedad, inseguridad, Buenos Aires, Paidós, 2013; Guy Standing, Precariado, una carta de derechos, Madrid, Capitán Swing, 2014.

${ }^{19}$ FAO / CEPAL / OIT, op. cit.; Ximena Valdés, "Feminización del empleo y trabajo precario en las agriculturas latinoamericanas globalizadas", Cuadernos de Antropología Social, 41, Instituto de Ciencias Antropológicas, Sección de Antropología Social, Facultad de Filosofía y Letras, Universidad de Buenos Aires, 2015, 39-54.

${ }^{20}$ Por ejemplo: Mónica Bendini y Nélida Bonaccorsi (comps.), Con las puras manos. Mujer y trabajo en regiones frutícolas de exportación, Buenos Aires, La Colmena, 1998; Antonieta Barrón, Empleo en la agricultura de exportación en México, México, Juan Pablos, 1997.

${ }^{21}$ Cfr. FAO / CEPAL / OIT, op. cit.

${ }^{22}$ Idem.

${ }^{23}$ Robert Castel, El ascenso de las incertidumbres. Trabajo, protecciones, estatuto del individuo, Buenos Aires, Fondo de Cultura Económica, 2010; Miguel Murmis, "Cuestión social y lazos sociales”, en Mónica Bendini, Josefa Salete, Miguel Murmis y Pedro Tsakoumagkos (comps.), El campo en la sociología actual: una perspectiva latinoamericana, Buenos Aires, La Colmena, 2003, 53-76; Hernán Cuevas, "Precariedad, precariado y precarización. Un comentario crítico desde América Latina a The Precariat. The New Dangerous Class de Guy Standing”, Revista Polis [en línea], 40, Santiago, CISPO / Universidad de los Lagos, 2015, publicado: 16 mayo 2015, consultado: 20 agosto 2015, disponible en Internet: <http://polis.revues.org/10754>.

${ }^{24}$ Pamela Caro, "El caso de Chile", en FAO / CEPAL / OIT, op, cit., 143-251. 
que se suman a intoxicaciones en los potreros y frigoríficos, y a padecimientos laborales por problemas asociados al trabajo en cadena en los packing de frutas ${ }^{25}$.

De este fenómeno ampliamente extendido, naturalizado y normalizado, tanto para el Estado como para el empresariado e incluso para buena parte de los trabajadores, puede hacerse una doble lectura: por un lado, muestra la modificación de los patrones de reproducción de las familias, que dependían del ingreso masculino ${ }^{26}$ mientras hoy se hace visible la coprovisión económica de los hogares. Por otro, el salario de las mujeres, aunque logrado bajo deficientes condiciones laborales y largas jornadas ${ }^{27}$, las dota de autonomía y libertad, lo que produce cambios en los patrones de autoridad en la familia, tensionando los fundamentos del patriarcado: el control masculino sobre las mujeres. Los costos de tales transformaciones son altos: extenuantes jornadas laborales, migraciones para "hacerse el salario", padecimientos laborales que a menudo se traducen en una forma de "ganarse la vida para perderla" 28 . Es lo que hemos llamado "emancipación precaria"29, atendiendo a la precarización del empleo agrícola temporal, pero a la vez a los grados de independencia que logran las mujeres con el salario obtenido a costa de la intensificación del trabajo y la extensión de la jornada laboral en contextos de "flexibilidad salvaje",30. En Chile, estas situaciones se vieron favorecidas por el Plan Laboral de 1979 y una legislación que, aunque ha incorporado modificaciones, preserva trabas a la negociación colectiva de los temporeros, frenando así el mejoramiento de las condiciones de trabajo ${ }^{31}$. A esto se suma la baja densidad sindical, en general, junto a la

\footnotetext{
${ }^{25}$ Ximena Valdés y Carmen Gloria Godoy, "Mujeres de cuerpos dañados: las temporeras de la fruta en Chile", ponencia en GT 17, Antropología del trabajo y de los trabajadores/as. Intersecciones en los entramados del poder, VIII Jornadas de Investigación en Antropología Social Santiago Wallace (27-29, julio, 2016: Buenos Aires, Argentina), Universidad de Buenos Aires, 2016.

${ }^{26}$ Ximena Valdés, La vida en común. Familia y vida privada en Chile y el medio rural en la segunda mitad del siglo XX, Santiago, LOM, 2007.

${ }^{27}$ La incorporación de las mujeres al trabajo remunerado es uno de los ejes que sustentan las actuales políticas de igualdad entre hombres y mujeres: autonomía e independencia figuran entre los argumentos que sostienen su ingreso al mercado de trabajo. Sin embargo, a pesar de la instalación de la idea de igualdad en los discursos y las políticas públicas desde hace ya un cuarto de siglo, la gran mayoría de las mujeres que trabajan en forma remunerada están situadas en los niveles inferiores de ingresos y en empleos precarios.

${ }^{28}$ Robert Castel, "Las transformaciones del trabajo en la sociedad capitalista actual”, en Robert Castel en la Cátedra Unesco. Las transformaciones del trabajo, de la producción social y de los riesgos en un período de incertidumbre, Buenos Aires, Siglo XXI / Instituto Di Tella, 2010, 86.

${ }^{29}$ Ximena Valdés, "Contra el desperdicio de la experiencia social: las temporeras y su acción colectiva", en Julio Pinto (ed.), Mujeres. Historias chilenas del siglo XX, Santiago, LOM, 2011, 117-140.

${ }^{30}$ Enrique de la Garza, Reestructuración productiva y respuesta sindical en México, México, IIE-UNAM / UAM-I, 1993, califica de "salvaje" a una flexibilidad que recurre a distintos métodos de coacción de los trabajadores para lograr su completa disponibilidad en términos de horarios y ritmos de trabajo.

${ }^{31}$ La VIII Encuesta ENCLA señala: “en la mayor parte de las empresas no hay ni ha habido un sindicato. La escasa presencia de sindicatos en el conjunto de las empresas que opera en Chile es una realidad que ha sido puesta en evidencia por esta encuesta desde su primera versión, hace ya 17 años, y que aun con variaciones, se ha mantenido acotada con el paso del tiempo" (157). La encuesta muestra que a mayor sindicalización hay mejores condiciones de trabajo y salarios (194). En las ramas de agricultura, silvicultura, pesca y caza hay menor proporción de instrumentos vigentes, como contratos o convenios colectivos, que en otras ramas (solo 2,3\%); en 40,9\% de las empresas de esta rama ocurren accidentes del trabajo, siendo así una de las de mayor accidentabilidad; también en ella se encuentran los salarios más bajos: 7\% de sus trabajadores gana menos del
} 
debilidad de las agencias estatales para fiscalizar a las empresas, lo que sumado a la heterogeneidad de este sector laboral, frena la constitución de actores sociales que reclamen por mejores y mayores derechos.

\subsection{Trabajo de las mujeres, autonomía con alto costo}

Las trabas para el logro de mayores derechos laborales para las temporeras coexisten, sin embargo, con discursos públicos que incentivan la incorporación de las mujeres al mercado laboral. Estos discursos, paradójicamente, traducen una política de reconocimiento de las mujeres como sujetos de derechos ${ }^{32}$. Con este reconocimiento, logrado por el conjunto de las mujeres, se han obtenido mayores espacios de autonomía y libertad en la vida privada y familiar con respecto al pasado, cuando las mujeres estaban enteramente sujetas a su lugar en la familia patriarcal como hijas, madres o esposas ${ }^{33}$. En este contexto, se favorece y promueve el trabajo de las mujeres - para combatir la pobreza e incentivar su autonomíaocultando el hecho de que las temporeras trabajan intensiva y temporalmente en la agricultura, cuando el estatus del trabajo se ha devaluado y ha desaparecido el "compromiso social del capitalismo industrial" ${ }^{34}$.

Se trata de un "reconocimiento" sin "redistribución", en la conceptualización de Nancy Fraser, lo que sitúa a este sector laboral, siguiendo a Robert Castel, más como "precariado" que como "asalariado". Frente al incremento de las incertidumbres, la desafiliación, la descolectivización y la "institucionalización de la precariedad" ", Castel sugiere que la única forma posible de luchar contra las consecuencias de la reorganización del trabajo en el

salario mínimo (SM); 11,9\% un SM; 34,1\% gana de 1 a 1,5 SM; 20,4 \% de 1,5 a 2 SM (100). ENCLA 2014, Santiago, Dirección del Trabajo, 2015.

${ }^{32}$ El reconocimiento es un tema de justicia tratado como una cuestión de estatus social. No ser reconocido implica una negación de la identidad, lo que impide la participación como iguales en la vida social. Las instituciones sociales son las encargadas de plantear estrategias que hagan posible la igualdad de condiciones de los diferentes grupos identitarios. Nancy Fraser y Axel Honneth, ¿Redistribución o reconocimiento?, Madrid, Morata, 2006; Nancy Fraser, “¿De la redistribución al reconocimiento? Dilemas en torno a la justicia en una época 'postsocialista"”, en Nancy Fraser, Iustitia Interrupta. Reflexiones críticas desde la posición “postsocialista”, cap. I, Bogotá, Siglo de Hombres, 1997, 17-54.

${ }^{33}$ Derivado de esa condición, las mujeres rurales fueron solo derechohabientes, es decir, lograron un estatus de protección de manera indirecta, por los vínculos conyugales o filiales con el trabajador/jefe de hogar. Los Censos agrícolas muestran variaciones en el empleo femenino con una tendencia hasta los años sesenta a la disminución del trabajo remunerado. El Censo Agrícola 1935-1936 informó que la mayoría de los trabajadores agrícolas vivían en las grandes explotaciones (256.054 frente a 95.391 "afuerinos", 27\% del total); $19,5 \%$ de los trabajadores permanentes -inquilinos- eran mujeres, 19,5\% eran trabajadoras temporales residentes (familiares de inquilinos) y 13,9\% eran afuerinas. Entre este censo y la Reforma Agraria se masculinizó la fuerza de trabajo, mientras que en el período entre 1965 y 1976 aumentaron en 4.000 las asalariadas temporales, dándose inicio ese último año, con la Contrarreforma agraria, al proceso de feminización de la fuerza de trabajo. Ximena Valdés, "Los procesos de incorporación y exclusión de las mujeres al mercado de trabajo agrícola", en Ximena Valdés et al., Sinopsis de una realidad ocultada, Santiago, CEM, 1987, 23-50.

${ }^{34}$ Castel, op. cit., 2010, 89.

${ }^{35}$ Castel, ibid., 91.

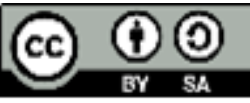


capitalismo contemporáneo “dependerá en gran medida del rol que puedan jugar las organizaciones de los trabajadores asalariados"36.

\section{Enmarque: un pasado cercano de conquistas y de pérdidas}

\subsection{El tiempo de los sindicatos: la Reforma Agraria}

Este año 2017 se conmemoran cincuenta años de la promulgación de la Ley de Reforma Agraria y de Sindicalización Campesina en Chile. ${ }^{37}$ Hasta entonces la historia social y política chilena estuvo marcada por la exclusión de los trabajadores del campo ${ }^{38}$, dado que todo intento por sindicalizarse fue frenado por los grandes propietarios de la tierra ${ }^{39}$. En cambio, durante la Reforma Agraria, emprendida entre los años 1964 y 1973, se incorporaron a la vida social y política cerca de 300.000 campesinos, que fueron parte de las confederaciones sindicales surgidas tras la Ley 16.625 de Sindicalización Campesina de 1967.

A un año de promulgada esta Ley, había 76.536 trabajadores adscritos a las confederaciones campesinas nacionales creadas entre 1967 y 1968: Ranquil, Triunfo y Libertad, más una de nivel provincial. Ranquil estaba vinculada a los partidos Comunista y Socialista, y Triunfo y Libertad a la Democracia Cristiana y a la Iglesia Católica. Todas las confederaciones fueron apoyadas desde una institucionalidad instalada en la Dirección del Trabajo, con el Fondo de Educación y Extensión Sindical (FEES), que reunía los dineros recaudados por ley con el aporte de un $2 \%$ de los trabajadores y otro $2 \%$ de los patrones ${ }^{40}$. La sindicalización fue

\footnotetext{
${ }^{36}$ Castel, ibid., 97.

${ }^{37}$ Más allá de las influencias que tuvo la Alianza para el Progreso en favor de reformas agrarias para frenar posibles conflictos sociales en América Latina, hubo un alto consenso en Chile entre los partidos políticos para llevarla a cabo. Octavio Avendaño, "Los partidos frente a la cuestión agraria en Chile, 1967-1973", Política, 52: 1, Santiago, Instituto de Asuntos Públicos, Universidad de Chile, 2014, 93-122.

${ }^{38}$ Roberto Santana, Agricultura chilena en el siglo XX: contextos, actores y espacios agrícolas, Santiago, Centro de Investigaciones Diego Barros Arana, DIBAM, 2016, 169.

${ }^{39}$ Oscar Oszlak, La trama oculta del poder. Reforma agraria y comportamiento político de los terratenientes chilenos, 1958-1973, Santiago, LOM, 2016.

40 "El Fondo de Educación y Extensión Sindical, FEES, se gesta en torno a la ley de sindicalización campesina 16.625 del año 67 [...] surgió la idea de crear una institucionalidad autónoma [...] la Dirección del Trabajo les daría garantía a todos [...] fue un fuerte financiamiento bipartito entre empresarios y trabajadores, se establece que la cotización sindical es obligatoria, todo contrato de trabajo que se haga en el campo conlleva una cotización del $2 \%$ de los salarios, todo empresario debe pagar el $2 \%$ [...] eso aseguró que los sindicatos efectivamente tuvieran vida. [...] Eso lo distribuía la Dirección del Trabajo en cheques mensuales mediante un listado de representación que tenían que hacer todos los años, cuantos afiliados tenían, de acuerdo con eso le calculaban un porcentaje, lo que nosotros administrábamos era parte del FEES, la otra mitad había un consejo establecido por decreto ley donde estaban representadas la organizaciones y las universidades del Estado [...] para programas de alfabetización, que en ese momento era una necesidad esencial... con INACAP que era filial de la CORFO para capacitación técnica, con la Universidad Técnica del Estado para un programa cultural, el teatro campesino y otras cosas. Haciendo el resumen, las organizaciones tenían una doble entrada de ingresos que les daba poder, los recursos propios destinados a la organización y los recursos que venían detrás para la capacitación y las asesorías técnicas, contrataban abogados, contadores y secretarias, y dinero para infraestructura, arriendo de locales, compra de máquinas de escribir, que era el
} 
gravitante durante la Reforma Agraria. Entre el año 1963 y 1970, los trabajadores sindicalizados pasaron de 1.500 a 140.293 , y en 1972 llegaron a $253.531^{41}$. Poco antes del golpe de Estado se hablaba de 300.000 trabajadores sindicalizados. El sello de la sindicalización en el campo fue marcadamente masculino ${ }^{42}$, solo 5,6\% de los participantes en estas organizaciones eran mujeres ${ }^{43}$.

De hecho, en el ámbito sindical se les reservó a las mujeres un lugar en los Departamentos Femeninos $^{44}$ de las confederaciones. Desde la matriz sindical se estableció una separación por género de funciones, así como también lo hizo el Estado, que durante la Reforma Agraria promovió los Centros de Madres para fomentar la asociatividad femenina vinculada a la condición materna, la gestión del hogar y la participación en la comunidad local y barrial ${ }^{45}$.

Ello contribuyó a afirmar una masculinidad adscrita al trabajo, al acceso a derechos laborales, a la tierra y otros recursos productivos y simbólicos, de tal forma que las políticas públicas reprodujeron los patrones culturales sexuados de la cultura campesina ${ }^{46}$ y el desigual acceso a la propiedad de la tierra de hombres y mujeres ${ }^{47}$. Las mujeres fueron abandonando las labores agrícolas como inquilinas y asalariadas para transformarse en dueñas de casa ${ }^{48}$, en el marco de un proceso - que se arrastraba desde los años cincuenta- de proletarización del inquilinaje, reducción del acceso a la tierra y a regalías ${ }^{49}$ y de cambios tecnológicos en la ordeña que masculinizó esa labor ${ }^{50}$.

No obstante, el mejoramiento de las condiciones de vida, el acceso a la tierra, la mayor escolaridad de hijos e hijas de campesinos y trabajadores agrícolas se cuentan entre los logros de la Reforma. Esta política redistributiva y democratizadora contribuyó a acentuar las brechas de género $^{51}$, en coherencia con el papel asignado a hombres y mujeres en la sociedad salarial. De hecho, durante el período de la Reforma Agraria se extendió a la población rural

instrumento de la época, y camionetas que era para trasladarse en el campo, era harta plata." Entrevista a Oscar Torres, encargado de FEES 1967-1973, 11 de octubre de 2016.

${ }^{41}$ Solon Barraclouh y Manuel Fernández, Diagnóstico de la Reforma Agraria chilena, México, Siglo XXI, 1974.

42 Ibid., 176, 178.

${ }^{43}$ Ibid., 179.

${ }^{44}$ Patricia Garret, "La Reforma Agraria. Organización popular y participación de la mujer en Chile, 19641973”, en Magdalena León (ed.), Las trabajadoras del agro, Bogotá, ACEP, 1985.

${ }^{45}$ Verónica Oxman, "La participación social de las mujeres rurales", Santiago, GIA, 1983 (documento de trabajo); Carmen Gloria Aguayo, Des chiliennes. Des femmes en lutte au Chili, París, Editions Des Femmes, 1982; Teresa Valdés, “Centros de Madres ¿Sólo disciplinamiento?”, Santiago, FLACSO, 1989 (documento de trabajo, 416),

${ }^{46}$ Pierre Bourdieu, Le bal des célibataires. Crise de la société paysanne en Béarn, París, Seuil, 2002.

${ }^{47}$ Magdalena León y Carmen Diana Deere, Género y derechos de las mujeres a la tierra en Chile, Santiago, CEDEM, 1999.

${ }^{48}$ Valdés, 1987, op. cit.

${ }^{49}$ Pablo Ramírez, Cambios en las formas de pago a la mano de obra agrícola, Santiago, ICIRA, 1968.

${ }^{50}$ Ximena Valdés, La posición de la mujer en la Hacienda, Santiago, CEM, 1988.

${ }^{51}$ Valdés, 2007, op. cit.; Heidi Tinsman, La tierra para el que la trabaja, Santiago, LOM 2009. 
la concepción del "salario familiar y la maternidad moral",52 conforme las concepciones sobre los géneros que acompañó el período de industrialización del país ${ }^{53}$.

La Reforma Agraria constituyó el último aliento redistributivo que hubo bajo el modelo de sustitución de importaciones. El acceso a la tierra para los inquilinos, los derechos laborales para los asalariados y el crédito y la asistencia técnica para los pequeños productores tradicionales y los del sector reformado constituyeron los pilares de las políticas públicas durante el período de realización de una de las reformas sociales de mayor envergadura del siglo XX, dirigida a la liquidación del latifundio y del poder político de los hacendados.

\subsection{Erosión de la organización sindical}

Los procesos de reparto de tierra, así como la organización sindical de los trabajadores fueron frenados con el golpe de Estado de $1973^{54}$. La dictadura congeló el sindicalismo, formuló decretos punitivos para los dirigentes sindicales, asesinó a varios de ellos, eliminó las formas colectivas de explotación de las tierras expropiadas al latifundio y asignó parcelas en propiedad individual a quienes no fueron juzgados como responsables de las movilizaciones de esos años. La represión comprometió a muchos dirigentes sindicales y el Decreto 198 dictado por la Junta Militar el 29 de diciembre de 1973 impuso la restricción sindical hasta la dictación del Plan Laboral de 1979, que eliminó el financiamiento a las organizaciones sindicales. Por otro lado, el Decreto 208 prohibió la asignación de tierras a dirigentes campesinos que hubiesen participado en "tomas de fundos".

Así, el Plan Laboral eliminó la base territorial del sindicalismo agrario y estipuló que habría sindicatos de empresa, interempresa e independientes o transitorios para los trabajadores de temporada, sin derecho a negociación colectiva, cuestión vigente hasta ahora. Con ello se logró el viejo anhelo de los gremios patronales de inhibir la organización sindical en el campo $^{55}$. El sindicalismo agrario nunca recuperó ni el papel ni el lugar que tuvo durante la Reforma Agraria. En diciembre de 1989, a diez años del Plan Laboral de la dictadura, había solo 41.789 trabajadores agrícolas sindicalizados, 15\% de los que hubo en 1972; el año 1992, recién recuperada la democracia, aumentó levemente su participación llegando a 50.331 sindicalizados, equivalente a 18\% de los trabajadores sindicalizados en 1972.

Entre el golpe de Estado y el año 1990, las Confederaciones Sindicales surgidas durante la Reforma Agraria se reestructuraron. Sobrevivieron muy disminuidas bajo la dictadura, al alero de la Iglesia Católica, agrupadas en la Comisión Nacional Campesina (CNC), que más

\footnotetext{
52 Jack Goody, La evolución de la familia y el matrimonio en Europa, Barcelona, Herder, 1986; Jack Goody, La familia europea, Barcelona, Editorial Gráfica, 2002.

53 Karen Rossemblat, "Por un hogar bien constituido. El Estado y su política familiar en los Frentes Populares", en Lorena Godoy (ed.), Disciplina y desacato, Santiago, SUR / CEDEM, 1994; Leora Auslander y Michele Zacarini-Fournel, Différence des sexes et protection sociale, XIX et XX siècles, Saint-Dennis, Presses Universitaires de Vincennes, 1995; Gisele Bock y Pat Thane (eds.), Maternidad y políticas de género. La mujer en los Estados de bienestar europeos, Valencia, Cátedra, 1991.

${ }^{54}$ José Bengoa, Historia rural de Chile Central. Crisis y ruptura del poder hacendal, tomo II, Santiago, LOM, 2015.

${ }^{55}$ Oszlak, op. cit.
} 
tarde daría lugar al Movimiento Unitario Campesino y Etnias de Chile (MUCECH). Este último cobijó a las antiguas Confederaciones Campesinas que, a su vez, se unieron o dividieron, según el caso. En este tipo de asociatividad heredera de la Reforma Agraria, las mujeres continuaban agrupadas en los Departamentos Femeninos de las Confederaciones Sindicales.

El proceso de modernización que se produjo en Chile bajo el neoliberalismo y la globalización de manera coercitiva no admitió, lograda la democratización formal, cambios sustantivos en el ámbito sindical. La antigua presión de los gremios patronales por inhibir la sindicalización en el campo ${ }^{56}$ quedó consagrada institucionalmente en el Plan Laboral de 1979 vigente hasta la fecha. En este escenario "gran parte de la sociedad carece de condiciones de organización que permitan la formación de instituciones asociativas e identidades colectivas" ${ }^{\prime 57}$, lo cual afecta a todos los sectores y ramas de la economía. En el ámbito de la agricultura, silvicultura, pesca y caza, la proporción de sindicalizados ha decrecido en los últimos años llegando a poco más de $10 \%$ del número de trabajadores que estaban sindicalizados en 1972 (véase Gráfico 1).

\section{Gráfico 1: Sindicalizados en agricultura, silvicultura, pesca y caza, 1990-2014}

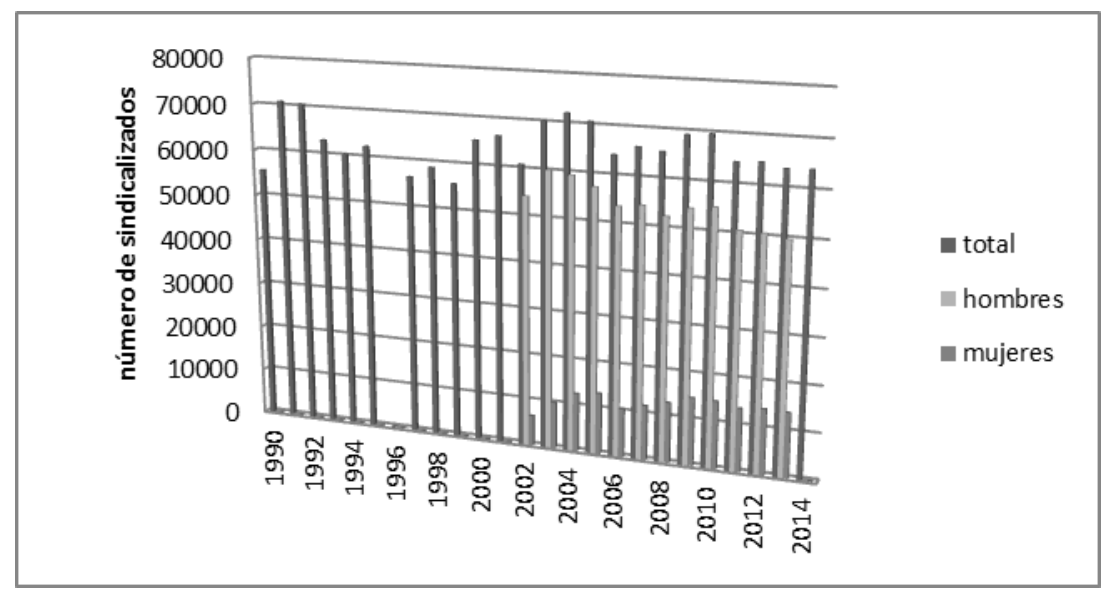

Fuente. Elaboración propia a partir de datos de la Dirección del Trabajo ${ }^{58}$

En este contexto de des-sindicalización que acompaña el proceso de flexibilidad y precarización laboral, la proporción de mujeres sindicalizadas, en cambio, ha aumentado en varias ramas y sectores ${ }^{59}$. En la agricultura y ramas afines, aumentó a $22 \%$ del total de los sindicalizados, proporción bastante mayor al 5,6\% que alcanzó en el año 1972, en plena

\footnotetext{
${ }^{56}$ Avendaño, op. cit., 93.

${ }^{57}$ Carlos Ruiz, De nuevo la sociedad, Santiago, LOM, 2015, 60.

${ }^{58}$ No se encontraron datos por sexo entre 1990 y 2000

${ }^{59}$ Verónica Riquelme, Más mujeres en los sindicatos. Sectores con alta sindicalización femenina, Santiago, Dirección del Trabajo, 2015.
} 
Reforma Agraria ${ }^{60}$. Sin embargo, más de la mitad de las mujeres sindicalizadas están afiliadas a sindicatos independientes y transitorios, lo que explica la escasa capacidad de negociación dadas las trabas de la legislación laboral a través de atribuciones muy limitadas a este tipo de sindicatos (lo que atenta contra el Convenio Internacional de la OIT 154 de 1981 sobre negociación colectiva $\left.{ }^{61}\right)$.

Es en este contexto de impedimento de negociaciones colectivas para las asalariadas agrícolas de temporada, de des-sindicalización en todos los sectores y ramas de la economía, de inclusión de las pocas mujeres sindicalizadas en sindicatos sin poder alguno frente al empresariado, que surge ANAMURI. Esta organización crea una estrategia de acción colectiva que se traduce en una suerte de "contraloría laboral" instalada en la sociedad civil, que se manifiesta, entre otras acciones, en denuncias de las condiciones de trabajo imperantes en el agro como forma de encarar la indefensión y las dificultades de organización de las asalariadas agrícolas.

\section{Re-enmarque: las transformaciones del agro y un nuevo actor social}

\subsection{Emergencia de un nuevo actor social}

Los problemas que enfrentan las temporeras comenzaron a hacerse visibles en los años ochenta; obedecían a la precarización y desregulación del empleo y fueron planteados y transformados en demandas por las mujeres rurales de las organizaciones sindicales y por $\mathrm{ONG}^{62}$ en los años 1986 y $1990^{63}$.

El fin de la dictadura contribuyó a generar condiciones para avanzar en procesos emancipatorios ${ }^{64}$ basados en reformas legales dirigidas a resituar a las mujeres en igualdad de condiciones con respecto de los hombres. Una nueva institucionalidad estatal ${ }^{65}$ se alineó

\footnotetext{
${ }^{60}$ Solon Barraclouh y Manuel Fernández, op. cit.

${ }^{61}$ Riquelme, op. cit.

${ }^{62}$ Durante la dictadura, las ONG tuvieron un papel central en la lucha por la democracia y, como sostiene Louis Joignet, siguen teniéndolo como instrumentos de democratización y avances en justicia social. Louis Joinet, Mes raisons d'Etat. Mémoires d'un épris de justice, París, La Découverte, 2013.

${ }^{63}$ En el Primer Encuentro de la Mujer Rural, realizado en Punta de Tralca, organizado por los Departamentos Femeninos de las Confederaciones Sindicales del Agro, agrupadas en esos años en la Comisión Nacional Campesina. En este "participaron más de 3.000 mujeres y se realizaron más de 300 encuentros en la base y 7 encuentros regionales". Cfr. Francisca Rodríguez, "Sembradoras del mañana, vital fuerza en la organización sindical", Agricultura y sociedad, 5:87, Santiago, GIA / Academia de Humanismo Cristiano, 1987, 64-72; Ximena Valdés, "Campesinas", en Sonia Montecino y Josefina Rossetti (eds.), Tramas para un nuevo destino. Propuestas de las mujeres de los partidos de la Concertación a la democracia, Santiago, Concertación de Mujeres por la Democracia, 1990.

${ }^{64}$ Geneviève Fraisse, Los dos gobiernos: la familia y la ciudad, Madrid, Cátedra, 2013.

${ }^{65}$ Dentro de estas demandas figuró la creación de una institucionalidad avocada a las políticas públicas dirigidas a las mujeres. En 1991 se creó el Servicio Nacional de la Mujer (SERNAM) como instancia dirigida precisamente a crear políticas en favor de la equidad de género. Mecanismos como las oficinas de la mujer e instrumentos como los Planes de Igualdad entre hombres y mujeres van a caracterizar el reacomodo de la institucionalidad estatal y la generación de políticas públicas proclives a la igualdad en toda América Latina.
} 
con las agendas de las Conferencias Mundiales de la Mujer y la asunción, por parte de los Estados, de políticas de igualdad de género. Bajo este escenario, las reformas laborales fueron pocas y lentas. La nueva institucionalidad democrática creó, en cambio, programas de cuidado para los hijos e hijas de las temporeras, dados los problemas que acarreaba para las trabajadoras dejarlos solos mientras ellas trabajaban (1994) ${ }^{66}$. Años más tarde (2002), se extendió el derecho de las temporeras a la atención de salud en el sistema público (FONASA) siempre que tuvieran más de 60 días de cotizaciones previsionales ${ }^{67}$. Con respecto a las condiciones de trabajo, al igual que con el acceso a la salud, la presión ejercida por las mujeres organizadas fue logrando algunos cambios en las normas sanitarias respecto al uso de insumos tóxicos en las plantaciones y en la regulación de los sistemas de subcontratación. Mientras tanto, la legislación laboral se mantuvo inhibiendo la sindicalización de temporeros y temporeras. El carácter temporal del empleo, la flexibilidad laboral, las migraciones laborales, la composición multicultural y la competencia que impone la organización del trabajo entre los/as trabajadores/as son factores que dificultan aún más su organización.

En el nuevo escenario en que el Estado reformuló su institucionalidad creando el Servicio Nacional de la Mujer (SERNAM) se incorporaron ciertas reformas, acogiendo con ello demandas de las mujeres surgidas en dictadura (ley que penaliza la violencia intrafamiliar, nuevo régimen de matrimonio, filiación, etc.) y desechando otras (las reformas laborales). Así, algunos problemas y no otros se consideraron en el contexto de los límites impuestos por el modelo neoliberal. De esta manera, el cuestionamiento al modelo, en especial en relación con la flexibilidad laboral y la inseguridad que esta impuso en el mundo del trabajo, no fue parte de la agenda de la transición política de los años noventa. Hasta la fecha se mantienen condiciones de trabajo deficientes en la agricultura y la agroindustria y restricciones al sindicalismo que continúan frenando la organización de los/as trabajadores/as. Aun así, se manifiestan conflictos sociales, algunos a nivel local y otros a escala territorial, muchos de ellos por las consecuencias del extractivismo en los territorios ${ }^{68}$.

De esta manera, el aliento de ciertas políticas por parte del Estado o, por el contrario, su omisión, marginación o simplemente el hecho de socavar ciertas acciones ${ }^{69}$, son parte de las formas en que el Estado reprodujo, a su manera, el legado impuesto en el sector agrario con la dictadura cívico militar. El Estado construye verdaderas rutas de instalación de su acción operando a través de "clasificaciones sociales fundamentales, como la edad y el

\footnotetext{
${ }^{66}$ Programa del SERNAM, "Atención de los hijos de las temporeras en verano”, que luego se trasladó a la ejecución en los municipios.

${ }^{67}$ El presidente de la República Ricardo Lagos, tras haber asistido con su gabinete al Encuentro de las temporeras en el año 2002, anunció el establecimiento de un sistema de protección en salud para las temporeras.

${ }^{68}$ Franck Gaudichaud, Las fisuras del neoliberalismo chileno. Trabajo, crisis de la "democracia tutelada” $y$ conflictos de clase, Santiago, Tiempo Robado, 2015.

${ }^{69}$ Philip Corrigan y Derek Sayer, "El gran arco. La formación del Estado inglés como revolución cultural", en María Lagos y Pamela Calla (comps.), Antropología del Estado. Dominación y prácticas contestatarias en América Latina, La Paz, Cuadernos del Futuro. Informe sobre Desarrollo Humano, 2007, 40-16, p. 45.
} 
género [que] terminan sacralizadas en leyes, incrustadas en instituciones, rutinizadas en procedimientos administrativos y simbolizadas en rituales del Estado" ${ }^{70}$, tal como se verifica con ciertas acciones y omisiones que finalmente dependen de una voluntad política subordinada al modelo económico.

Algunas situaciones permitieron que organismos de la sociedad civil participaran de un debate dirigido a modificar este tipo de omisiones en escenarios proclives a la ampliación de la ciudadanía de las mujeres. A esto contribuyó la IV Conferencia Mundial de la Mujer (Pekín 1995), que brindó un fuerte impulso a la puesta en escena a nivel nacional de las demandas de las mujeres rurales. Este hecho, sumado a la presión de organizaciones sociales y ONG, consiguió que en 1997 se postularan en el SERNAM las "Propuestas de políticas de igualdad de oportunidades para las mujeres rurales", que fueron seguidas por la instalación de Mesas de Trabajo de la Mujer Rural a nivel nacional y regional. El fundamento que tuvieron los organismos de la sociedad civil para presionar al SERNAM radicó en la exclusión de estos sectores de mujeres del Plan de Igualdad de Oportunidades que orientaba las políticas públicas en favor de la "equidad de género" y que habían comenzado a instalarse en el país en los años noventa.

No obstante, estos instrumentos de carácter inclusivo surgidos por la presión de las organizaciones de la sociedad civil, no necesariamente lograron modificar las políticas públicas $^{71}$. Por el contrario, se transformaron en un ritual de Estado, que se borraba o reconstruía, mostrando una curva sinuosa que daba cuenta del interés o desinterés por las mujeres rurales y las asalariadas agrícolas según cada gobierno. Los problemas ligados a las condiciones de trabajo, la exposición de las mujeres en los campos, packing y frigoríficos a productos químicos altamente dañinos a la salud, las largas jornadas laborales para hacerse de un salario en la temporada, la informalidad de las relaciones laborales, la sujeción a subcontratistas, fueron más bien problemas puestos en el debate y la agenda pública por organizaciones sociales que reunían a mujeres rurales y ONG, sin dejar de lado a funcionarias públicas, especialmente de los servicios de salud que contribuyeron "desde dentro" del Ministerio de Salud a actuar en el mismo sentido. Con ello, como se verá más adelante, se lograron ciertos cambios normativos y legales en cuanto a condiciones de trabajo durante la década de 2000, con la actuación de ANAMURI, como ya se dijo, como figura de "contraloría laboral desde abajo" ante un Estado bastante ausente en las regulaciones al trabajo y la fiscalización de las empresas.

\subsection{Trayectoria organizativa y estrategias de acción colectiva}

Muchas mujeres pertenecientes a los sindicatos herederos de la Reforma Agraria se desprendieron de estos, dejando sus Departamentos Femeninos. Así, aunque contaban con la experiencia de la movilización social durante la Reforma Agraria, que se dio al tenor de la organización sindical de ese período (1964-1973), siguiendo esa huella, demarcan desde

\footnotetext{
${ }^{70}$ Idem.

${ }^{71}$ El INDAP ciertamente logró ampliar la política crediticia y de asistencia técnica hacia las mujeres rurales y modificar el monopolio de las políticas gubernamentales de que gozaban los pequeños productores hombres hasta el año 1990.
}

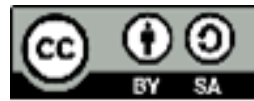


entonces fronteras con el sindicalismo tradicional. Después de varias décadas, pre y post dictadura, este proceso culminó en la creación de una organización de mujeres rurales e indígenas -ANAMURI- en el año 1998. La trayectoria de ANAMURI está ligada a la construcción de las demandas de las temporeras y de las denuncias de las condiciones de trabajo, que se remontan a los años de la dictadura, unida a un largo proceso de autonomización de las mujeres de las centrales sindicales campesinas que nacieron al alero de la Reforma Agraria.

El surgimiento de esta organización integrada por asalariadas, campesinas e indígenas, en cuyo centro se ubicaron las condiciones de trabajo de las temporeras, podría explicarse por distintos factores: un Estado reducido en su capacidad de brindar protecciones sociales y regulaciones, lo que limita las posibilidades de mejoramiento de las condiciones de trabajo; debilitamiento de un actor social que fue clave durante la Reforma Agraria: el campesinado y su base sindical ${ }^{72}$, y por la emergencia de nuevos movimientos sociales, comportamientos defensivos colectivos, estrategias de resistencia o simplemente acción colectiva. Estos surgieron a raíz de la implementación del modelo neoliberal y del carácter extractivo de muchas de las actividades de exportación localizadas en espacios rurales ${ }^{73}$, que se dieron en paralelo a la restricción de derechos de los/as trabajadores/as consagrada con el Plan Laboral de 1979. En este marco, las asalariadas agrícolas quedaron sin lugar -ni como categoría laboral ni como género- y carentes de herramientas para transformar su condición de trabajadoras precarias en un contexto en que se promovió, desde los gobiernos postdictadura de esos años, el ingreso de las mujeres al mercado de trabajo, ya sea para favorecer su autonomía o para superar la pobreza.

La trayectoria de ANAMURI se inscribe en un proceso largo. En 1986, las mujeres de las Confederaciones Sindicales Campesinas realizaron el primer Encuentro de la Mujer Rural. Durante esa década surgía en Chile el movimiento de mujeres y feminista con una agenda marcada por la recuperación de la democracia y contra la discriminación por razones de sexo. En este contexto, quienes hasta entonces formaban parte de los Departamentos Femeninos de las Confederaciones Sindicales Campesinas comenzaron a plantear sus demandas desde su condición de mujeres, como trabajadoras y, además, como productoras $^{74}$.

Doce años después, algunas de las dirigentas de los Departamentos Femeninos de estas Confederaciones, junto a 54 mujeres de distintas organizaciones de base y sindicatos, localizados en diferentes regiones del país, decidieron "emanciparse" de la tutela masculina fundando en el año 1998 la Asociación Nacional de Mujeres Rurales e Indígenas.

Desde entonces ANAMURI despliega un conjunto de iniciativas de acción colectiva de resistencia a la precarización laboral en un contexto de feminización del mercado de trabajo

\footnotetext{
72 José Bengoa, "25 años de estudios rurales”, Revista Sociologías, 5:10, Porto Alegre, 2003, 36-98.

${ }^{73}$ Cfr. José Bengoa (ed.), Territorios rurales. Movimientos sociales y desarrollo territorial rural en América Latina, Santiago, RIMISP / Catalonia, 2007.

${ }^{74}$ Ximena Valdés, "Hacia la generización de las trabajadoras del agro", Agricultura y sociedad, 5: 87, Santiago, GIA / Universidad Academia de Humanismo Cristiano, 1987, 27-49.
} 
en la agricultura de exportación. Entre 1998 y 2001 se consolidó un número importante de organizaciones de base a lo largo del país, desde sindicatos de temporeras hasta organizaciones de distinto tipo, tanto campesinas como indígenas ${ }^{75}$. En adelante, ANAMURI desarrolló acciones colectivas en representación de una amplia gama de intereses entre los que destacan los de las temporeras de la fruta, en distintas escalas y frente a diferentes referentes.

\subsection{Rituales, acción colectiva y formas de representación}

\section{Día de la temporera: 26 de agosto}

El hito que va a constituir en ANAMURI un referente para las temporeras agrícolas y para el Estado, fue el Encuentro Nacional de Temporeras organizado por la Comisión de Asalariadas Agrícolas, acontecido el 26 de agosto de 2002 en el edificio Gabriela Mistral, con una amplia convocatoria (más de 1.600 trabajadoras en el corazón de Santiago), al cual fue convocado el entonces presidente de la República, Ricardo Lagos, y su gabinete. Allí se plantearon los problemas que enfrentaban las asalariadas temporales y se expusieron demandas en cuanto a salarios, condiciones de trabajo, salud laboral y subcontratación. Ese día fue instituido por ANAMURI como el Día de la Temporera.

Al año siguiente (2003), como modo de presionar al Poder Legislativo, se organizó una gran marcha de más de 500 mujeres en Valparaíso, que avanzó desde el puerto de embarque de frutas hasta el Congreso Nacional, donde, frente a diputados y senadores, ANAMURI expuso las condiciones de trabajo y las consecuencias de la subcontratación en la calidad del empleo. Para ello contaron con el apoyo de dos diputadas feministas.

Años después, en la vía pública, las mujeres de ANAMURI realizaron reiteradas protestas frente a empresas comercializadoras de agrotóxicos en sus sedes de Santiago. Con uniformes de fumigadores y bombas de fumigación entraron a las sedes de las empresas "fumigándolas", mostrando así una acción de denuncia en contra del uso indiscriminado de agrotóxicos.

Tiempo después, para encarar al empresariado exportador, un grupo numeroso de mujeres de ANAMURI ingresaron a un seminario organizado por asociaciones gremiales de exportadores (como la Asociación de Exportadores de Chile -ASOEX- y la Sociedad Nacional de Agricultura -SNA-). Con carteles de denuncia por los bajos salarios y envenenamientos con pesticidas y plaguicidas irrumpieron en medio del desarrollo de la actividad empresarial.

Cuestionando a los gremios empresariales agrícolas y exportadores, y también a las confederaciones sindicales, ANAMURI se opuso y denunció los fines que tenía el Estatuto del Temporero que se propuso para el debate parlamentario durante el gobierno de

\footnotetext{
${ }^{75}$ Las acciones colectivas analizadas en este texto corresponden solo a las temporeras o asalariadas agrícolas de temporada, no así a las iniciativas relacionadas con campesinas, indígenas o productoras.
} 
Sebastián Piñera, considerado como una herramienta paralela al Código del Trabajo que precarizaba aún más las condiciones de trabajo de las temporeras.

Como una actividad dirigida a la sociedad civil, cada 26 de agosto ANAMURI desarrolla actos en diversas ciudades del país (Curicó, Talca, Copiapó, Vicuña, etc.) para conmemorar el Día de la Temporera, actualizando en esta fecha la denuncia sobre las condiciones de trabajo, y a la vez, fomentando la organización social.

\section{Día de la no violencia contra las mujeres en el trabajo: 25 de noviembre}

A partir del año 2009, y de manera ininterrumpida, cada 25 de noviembre ANAMURI organiza los Tribunales Éticos ${ }^{76}$. Haciendo una resignificación de las consignas feministas que quedaron plasmadas en los 25 de noviembre como Día de la no violencia contra las mujeres, lo transforma en el Día de la no violencia hacia las mujeres en el trabajo. Con el fin de paliar la indefensión en que se encuentran las temporeras, despliega actividades en las que se denuncian las enfermedades y los accidentes laborales que afectan a las temporeras de la fruta. Estas actividades contemplan una investigación de los atropellos cometidos en contra de las trabajadoras, que luego es expuesta en un acto público destinado a dar a conocer y "juzgar" estos atropellos a los derechos de las trabajadoras - a veces con resultado de muerte- a través de la intervención de un jurado, que dicta una resolución que dirime sobre los agentes responsables de la vulneración de los derechos laborales. Los Tribunales Éticos se yerguen como espacios de denuncia ante las malas prácticas empresariales y la ineficacia del Estado y de las reparticiones públicas responsables, de modo tal de construir escenarios que permitan difundir situaciones que ponen en tela de juicio el ejercicio de justicia laboral por parte de un Estado inoperante y desarmado frente a los requerimientos de fiscalización a las empresas. Un acto público -generalmente realizado en universidades- en que se denuncian casos de trabajadoras afectadas por padecimientos laborales, conforma el escenario de los Tribunales compuestos por las trabajadoras, profesionales del mundo laboral, médicos, religiosos, parlamentarias/os, ONG, personas comprometidas con la defensa de derechos, que analizan cada caso y dan un veredicto ante una audiencia abierta a los y las trabajadores/as, estudiantes, profesionales y funcionarios públicos.

En la siguiente tabla se resumen los Tribunales Éticos que se han venido realizando:

\begin{tabular}{|l|l|l|}
\hline \multicolumn{2}{|c|}{ Tribunales Éticos } \\
\hline Año & Lugar de realización & Denuncia \\
\hline 2009 & $\begin{array}{l}\text { Santiago, Casa Central, } \\
\text { Universidad de Chile }\end{array}$ & $\begin{array}{l}\text { Denuncia de la muerte de Cecilia Ortiz, Frutícola } \\
\text { Atacama, Copiapó, fallecida tras inhalación de } \\
\text { amoníaco por rotura de cañería de frigorífico }\end{array}$ \\
\hline 2010 & $\begin{array}{l}\text { Santiago, Facultad de } \\
\text { Derecho, Universidad }\end{array}$ & $\begin{array}{l}\text { Denuncia de la violación de los derechos laborales } \\
\text { en Parral y San Clemente y de los retrocesos en }\end{array}$ \\
\hline
\end{tabular}

\footnotetext{
${ }^{76}$ Sistematización realizada por Angie Mendoza.
} 


\begin{tabular}{|c|c|c|}
\hline & Diego Portales & $\begin{array}{l}\text { materia de fiscalizaciones con el gobierno de } \\
\text { derecha. }\end{array}$ \\
\hline 2011 & $\begin{array}{l}\text { Santiago, Universidad de } \\
\text { Santiago de Chile }\end{array}$ & $\begin{array}{l}\text { Denuncia de la intoxicación por amoníaco en } \\
\text { frigorífico y daños graves en las vías respiratorias } \\
\text { de Flor María Contreras Beas, packing GESEX, } \\
\text { Frigorífico La Hornilla, Melipilla, y denuncia del } \\
\text { envío al Parlamento del Estatuto del Temporero } \\
\text { acordado entre gremios empresariales y } \\
\text { confederaciones sindicales. }\end{array}$ \\
\hline 2012 & $\begin{array}{l}\text { Santiago, Sede de la } \\
\text { Central Unitaria de } \\
\text { Trabajadores, CUT }\end{array}$ & $\begin{array}{l}\text { Denuncias de enfermedades laborales de las } \\
\text { trabajadoras del agro }\end{array}$ \\
\hline 2013 & $\begin{array}{l}\text { Santiago, en el marco del } \\
\text { Segundo Congreso de } \\
\text { ANAMURI }\end{array}$ & $\begin{array}{l}\text { Denuncia de Monsanto, plaguicidas, semilleros, } \\
\text { transgénicos y trabajo infantil }\end{array}$ \\
\hline 2014 & Santiago & $\begin{array}{l}\text { Denuncias de aumento de intoxicaciones con } \\
\text { plaguicidas, con apoyo de RAPAL }\end{array}$ \\
\hline 2015 & Copiapó & $\begin{array}{l}\text { Denuncia de trabajadoras sometidas al encierro } \\
\text { perimetral de los containers/dormitorios - } \\
\text { campamento La Capilla, de la Frutícola Atacama, } \\
\text { Copiapó, arrastrados por el aluvión, que causó la } \\
\text { muerte de al menos dos temporeras. Testimonio de } \\
\text { Claudia Contreras, víctima del aluvión de barro. }\end{array}$ \\
\hline 2015 & Talca & $\begin{array}{l}\text { Denuncia de intoxicaciones con plaguicidas, } \\
\text { intoxicaciones en Agrícola Fruto Sol, fundo San } \\
\text { Lorenzo, Linares; denuncia de vulneración de } \\
\text { derechos a mujeres migrantes, ONG Raíces, en } \\
\text { Frutícola Cabo de Hornos, Atacama. }\end{array}$ \\
\hline
\end{tabular}

En síntesis, ANAMURI denuncia los problemas que viven las trabajadoras y transmite sus demandas ante el Estado y el empresariado. Todavía insertas en las Confederaciones Sindicales, en los años ochenta, estas mujeres fueron quienes colocaron en la agenda pública el problema de los agrotóxicos y las consecuencias que estos productos químicos generaban en la salud de los y las trabajadores/as. Especial relevancia tuvo para quienes hoy lideran ANAMURI el problema de las malformaciones de los recién nacidos hijos de temporeros/as expuestos a fumigaciones. Una gran cantidad de denuncias se vienen haciendo desde esos años hasta hoy, lo que ha contribuido a eliminar algunos de los tóxicos de la llamada "docena maldita", pero no necesariamente el cumplimiento de las normas por parte de las empresas. 


\subsection{Incidencia}

El impacto alcanzado por ANAMURI ha variado en función de la porosidad de los distintos gobiernos y servicios públicos al apoyo de estas iniciativas o a frenarlas. Hubo cambios en materia de salud, en especial en el acondicionamiento de los servicios de salud a los nuevos problemas en salud laboral de las temporeras generados por los sistemas de trabajo y la exposición a agrotóxicos. Gradualmente se avanzó en materia de enfermedades profesionales, en el establecimiento de una red en salud para medir las intoxicaciones. Las estrategias de las mujeres de ANAMURI para lograr estos cambios en el Ministerio de Salud se orientaron a establecer alianzas con enfermeras y médicos salubristas. Ello permitió mantener presente en el ámbito público los problemas que enfrentaban las mujeres en los lugares de trabajo y el debate sobre los mismos.

No obstante, con el gobierno de Sebastián Piñera (2010-2014) se disolvieron los equipos que trabajaban en estas materias y, con ello, los apoyos que funcionarias del sector público brindaban a las trabajadoras. La inflexión que tuvo este tipo de denuncia pública bajo ese gobierno llevó a que ANAMURI tuviera que enfrentar una arremetida patronal (con apoyo de algunas organizaciones sindicales campesinas herederas de la Reforma Agraria) para oponerse a la creación del Estatuto del Temporero, que para ellas se traducía en una herramienta de mayor legitimación de la flexibilidad y la precarización laboral.

Entre los logros de esta estrategia, si se quiere, de carácter "gradualista" e "institucionalista", ANAMURI ha contribuido a que se extiendan las prestaciones en salud a las temporeras en el sistema público; a establecer normas de baños químicos en las plantaciones; a la dotación de casinos en las empresas, mejoramiento de campamentos y dormitorios para migrantes, normas para subcontratistas y al freno al establecimiento de dispositivos dirigidos a la sobreprecarización laboral (Estatuto del Temporero y enfrentamiento con gremios empresariales y organizaciones sindicales en espacios de interlocución creados por el gobierno) ${ }^{77}$.

En cuanto a la previsión social, uno de los temas claves de la agenda de las temporeras, en el año 2008 se estableció una pensión solidaria para hombres y mujeres pertenecientes al $60 \%$ de personas con ingresos más bajos y mayores de 65 años. Es una pensión que entrega el Estado a quienes nunca han cotizado y que comenzó a regir en julio de 2008. Las temporeras con discontinuidad anual de cotizaciones previsionales están cubiertas por esta pensión solidaria, lo que las iguala a cualquier mujer que no ha trabajado nunca en forma remunerada. Se adicionan puntos para las jubilaciones en función de los meses y años cotizados, no obstante, las jubilaciones son muy bajas por la discontinuidad de las cotizaciones a causa del carácter temporal del empleo.

\footnotetext{
${ }^{77}$ Ximena Valdés, Carmen Gloria Godoy, Ana López y Paula Raposo, "De la sindicalización campesina al estatuto del temporero. Pasado y presente en las luchas de los trabajadores agrícolas", Espacios, Revista de Geografía, 2:4, diciembre, Santiago, Universidad Academia de Humanismo Cristiano, 2012, 73-89.
} 
El rasgo institucionalista se explica porque ANAMURI no está fuera de las lógicas que ofrece el Estado y de los vínculos que el mismo Estado establece con las organizaciones campesinas. Es más, ANAMURI ha logrado obtener en los últimos años montos semejantes a los que se les asignan por proyectos a las viejas Confederaciones Sindicales, que ya no se vinculan para estos propósitos con la Dirección del Trabajo, dependiente de ese mismo Ministerio, como ocurría durante la Reforma Agraria, sino con el Instituto de Desarrollo Agropecuario (INDAP), perteneciente al Ministerio de Agricultura ${ }^{78}$. El financiamiento otorgado a las organizaciones por el INDAP depende del Programa de Gestión y Soporte Organizacional (PROGYSO) y el reparto del dinero a cada organización se basa en el número de los asociados declarados ${ }^{79}$. ANAMURI no se diferencia mayormente en el número de sus asociadas y de su presencia en casi todas las regiones del país de otras organizaciones, por lo cual recibe un financiamiento similar o menor a las Confederaciones Sindicales, que se han reestructurado y unido en organizaciones que cobijan a varias y en conjunto perciben sumas muy superiores a la que recibe esta organización de mujeres. Con todo, esta última logró constituirse en un referente en la materia para el Estado.

En términos de los desplazamientos institucionales, de la Dirección del Trabajo durante la Reforma Agraria al Instituto de Desarrollo Agropecuario, el giro es particularmente significativo, pues el apoyo estatal hoy se da desde la institucionalidad de promoción al desarrollo de la agricultura campesina y no desde aquella que protege los derechos laborales.

Tales estrategias se organizan en un contexto muy desfavorable a la organización social de los trabajadores y de un significativo proceso de des-sindicalización. No obstante, como ya se mencionó, algunas de sus líderes traen consigo la experiencia de haber vivido el proceso de la Reforma Agraria y son ellas quienes han mantenido viva la defensa de los derechos laborales.

\subsection{Cómo definir este tipo de acción colectiva}

Para comprender el carácter de la acción colectiva de ANAMURI parece necesario dejar de lado los marcos analíticos de la sociedad industrial y situarse en el denominado postfordismo, donde se hace más complejo clasificar los sentidos y alcances de las movilizaciones sociales. Es útil revisar algunos de los marcos con los cuales se ha estudiado la protesta popular en Latinoamérica y los avances en la conceptualización y reconceptualización de estos procesos, que en muchos casos han migrado desde la protesta social - de clase- a la protesta territorial enraizada en el extractivismo y en los fenómenos propios del neoliberalismo causados por la "acumulación por desposesión" 80 .

\footnotetext{
${ }^{78}$ INDAP en cifras, primer semestre 2016, Población usuaria, Organizaciones de representación campesina, Santiago, INDAP, p. 54, y datos obtenidos por transparencia de INDAP para el análisis de los montos asignados a cada organización por el programa PROGYSO y entrevista a Octavio Sotomayor, director de INDAP.

${ }^{79}$ Entrevista a Octavio Sotomayor, director de INDAP, octubre de 2016.

${ }^{80}$ David Harvey, El “nuevo” imperialismo: acumulación por desposesión, Buenos Aires, CLACSO, 2005.
} 
Tal como sostiene Neil Harvey ${ }^{81}$, en Latinoamérica "las luchas de los movimientos populares en pos de la dignidad, voz y autonomía son precisamente intentos por constituir al 'pueblo' como actor político [...] con el derecho a participar en el debate público y esgrimir 'su derecho a tener derechos', como lo entendió Hanna Arendt ${ }^{82}$.

Aunque ANAMURI se define como movimiento social y parte de un movimiento latinoamericano y con carácter global (a través de la Coordinadora de Organizaciones del Campo -CLOC/Vía Campesina-) ${ }^{83}$, las estrategias llevadas a cabo para presionar por el mejoramiento de las condiciones de trabajo de las temporeras se inscriben más bien en un tipo de acción colectiva de resistencia a la precarización laboral y a las nuevas formas de exclusión generadas por el neoliberalismo. Lo hacen amparadas en una amplia base social a lo largo del país que les permite comprender tanto las consecuencias de la matriz extractivista en los territorios y las poblaciones, como los efectos en los cuerpos y la salud de las asalariadas ${ }^{84}$. Por su parte, se ve disminuidas a las organizaciones sindicales creadas durante la Reforma Agraria y aún bajo dirección masculina en relación con lo que fueron. Francisca Rodríguez, dirigente de ANAMURI, señala: "[...] los compañeros llegan derrotados, ven lo importante que fueron como organización y cómo están ahora y piensan que es imposible llegar a ser lo mismo que antes. Nosotras no, nosotras no tenemos pasado, somos presente y futuro y hemos construido también teniendo en cuenta las malas experiencias de las organizaciones. Entonces nos proyectamos".

Volviendo a lo señalado más arriba, no se trata de los clásicos movimientos sociales de la sociedad industrial, como el obrero, basado en el sindicalismo, ni de los movimientos culturales del capitalismo tardío (feminista, ambientalista, pacifista, etc.), sino de acciones colectivas que se enmarcan en lo que se entiende como movimientos populares. David Slater $^{85}$, apoyándose en Ernesto Laclau y Chantal Mouffe, sostiene que la politización de lo social condujo a movimientos sociales autónomos, a partir de lo cual se disolvió la separación tradicional entre lo político y lo social. Estos nuevos movimientos, siempre según su análisis, constituyen respuestas a nuevas formas de subordinación propias del capitalismo contemporáneo. Se definen por sus prácticas políticas; tienen una orientación institucionalista; utilizan estrategias gradualistas para redefinir los parámetros de lucha y ensanchar los horizontes de lo que es políticamente posible; promueven mayor igualdad entre los sexos y tienden a agrupar a gran cantidad de mujeres. Se trata de un tipo de lucha que tiene lugar en los intersticios de un cambiante "terreno legal e institucional"86. Slater considera que estos nuevos movimientos llamados "populares" se caracterizan por su

\footnotetext{
${ }^{81}$ Neil Harvey, La rebelión de Chiapas. La lucha por la tierra y la democracia, México, ERA, p. 56.

${ }^{82}$ Hannah Arendt, Los orígenes del totalitarismo, Madrid, Taurus, 1998.

83 “ANAMURI es un movimiento social... Somos mujeres en movimiento, estamos construyendo el movimiento de mujeres. Nos nutrimos del trabajo internacional (CLOC/Vía Campesina) en cuanto la fuerza que van tomando los temas centrales en la creación de una política anti modelo neoliberal". Entrevista a Francisca Rodríguez, ANAMURI, agosto de 2015.

84 "Nos validamos en regiones, llegamos con mucha más ropa para sentarnos en las mesas de negociaciones, con la fuerza que nos da el haber demostrado que somos una organización nacional" (idem).

${ }^{85}$ Citado por Harvey, op. cit., 38.

${ }^{86}$ Como señala Forewarks, 1990, citado por Neil Harvey, op. cit., 37-38.
} 
resistencia al poder en un nuevo entorno político más excluyente, frente al cual se han desarrollado nuevas estrategias y prácticas de resistencia.

\section{A modo de cierre}

Aunque el acceso de las mujeres al salario contribuya a su autonomía económica y a su emancipación de la tutela masculina, este proceso se enmarca históricamente en el tránsito de la subordinación hacendal -sistema de dominación de larga duración en el país- a una "emancipación precaria", enmarcada en el neoliberalismo. De un lado hay un cierto "reconocimiento" hacia las mujeres y sus derechos como parte de los derechos humanos (como lo entiende Fraser), pero sin que haya "redistribución", esto es, un marco de justicia que contemple, por ejemplo, normas y regulaciones en el plano del mercado de trabajo y los derechos laborales que les fueron conculcados a los trabajadores agrícolas temporales con el Plan Laboral de 1979 durante la dictadura y que no les han sido restituidos por las legislaciones laborales posteriores aprobadas en la postdictadura. El reconocimiento como sujetos de derechos, visible en un conjunto de dispositivos, leyes, políticas y discursos públicos (como las leyes de penalización de la violencia doméstica y sexual, el divorcio, el acuerdo de vida en común, la nueva ley de filiación, etc.), contribuyó al avance en independencia y ha empujado a las mujeres a organizarse en forma autónoma una vez que percibieron que su existencia en los Departamentos Femeninos sindicales frenaba su participación social y el reclamo por sus derechos como clase y género. Sin embargo, se trata de un proceso de afirmación de las mujeres como sujetos de derecho que no ha ido necesariamente acompañado de cambios sustantivos en las condiciones laborales, puesto que la mayoría de las mujeres, como es el caso de las temporeras, accede al empleo precario que mantiene deficientes condiciones de trabajo, informalidad laboral, largas jornadas, brechas salariales entre hombres y mujeres, condiciones laborales nocivas para la salud, en un contexto en que se cruza el género, la etnia, la raza, la nacionalidad y la condición migratoria, lo que a la vez dificulta la organización. A esto se agregan las consecuencias de un tipo de producción agrícola cuyos insumos (agrotóxicos, pesticidas, plaguicidas) dañan los cuerpos y la salud de las y los trabajadores sumado al tipo de labor en cadena que genera dolencias corporales, como tendinitis y otras, dadas por el tipo de movimiento y condiciones laborales en los packing y potreros a campo abierto.

No obstante, la acción colectiva desplegada no ha sido estrictamente inútil. Se han modificado condiciones de trabajo (baños en los potreros a 50 metros, casinos, bloqueadores solares, regulación de agrotóxicos, etc.); se ha regulado la subcontratación; se ha dado acceso a las temporeras al sistema de salud y a guarderías infantiles, ha aumentado la formalización del empleo, aun cuando se conserven sus características precarias.

Slater y otros autores ${ }^{87}$ identifican una variada cantidad de movimientos arguyendo que estos movimientos son definidos por las maneras en que rompen con las prácticas y las teorías tradicionales de la acción colectiva, discutiendo con esta posición las ideas de Alain Touraine $^{88}$, quien reservó la categoría de "movimientos sociales" a las luchas por la

\footnotetext{
${ }^{87}$ David Slater, Nuevos movimientos sociales y el Estado en Latinoamérica, Amsterdam, CEDLA, 1985.

${ }^{88}$ Alain Touraine, El retorno del actor, Buenos Aires, Editorial Universitaria, 1988.
} 
historicidad o por el conjunto de modelos culturales que gobiernan las prácticas sociales. Como sabemos, esta categorización fue aplicada a las sociedades postindustriales de la Europa occidental. En ese contexto, los movimientos sociales son simplemente el trabajo que la sociedad hace sobre sí misma, es decir, la lucha por los sentidos culturales, las identidades y la diferencia. Las divisiones de clase no ocupan, como lo hicieron en la sociedad industrial, el centro del conflicto social, como le correspondió al movimiento obrero. En su lugar, se instalan las críticas a la modernidad que plantean un amplio abanico de actores, entre ellos pacifistas, feministas, ambientalistas, minorías étnicas y sexuales, y movimientos culturales.

Dadas las diferencias, a lo menos parciales, con lo que acontece en América Latina, lo que se denomina genéricamente en nuestro continente como movimientos sociales podría corresponder mejor a "comportamientos defensivos colectivos", como los entiende Slater. Esta categoría se refiere a las acciones dirigidas al Estado con el objeto de solucionar demandas particulares, aunque Touraine se inclina por definirlas como "luchas sociales" dirigidas a transformar políticas gubernamentales. Otros autores prefieren, en cambio, hablar de "movimientos populares". Estos últimos buscarían establecer al pueblo como un actor político que persigue representación sin perder la autonomía. Esta sería una estrategia gradualista que define los parámetros de lucha ensanchando los horizontes de lo que es políticamente posible. Este tipo de lucha tiene lugar, para Joe Foweraker y Anne L. Craig ${ }^{89}$, en los intersticios de un cambiante terreno legal e institucional.

En este marco, en aquellas acciones que están inscritas en las luchas de los movimientos populares, tanto la voz como la autonomía son intentos por constituir al pueblo como actor político. Como afirma Judith Butler "el carácter corporizado del pueblo resulta ser muy importante para el tipo de demanda que se formula" ya que:

[...] cuando aquellos que se enfrentan con una perspectiva acelerada de precariedad salen a la calle y comienzan a protestar diciendo "nosotros el pueblo" están afirmando que ellos, aquellos que están allí y hablan, se identifican como "el pueblo" [... y] afirman una forma de igualdad frente a la desigualdad creciente, y no simplemente por enunciar la frase, sino por darle cuerpo a la igualdad de cualquier manera posible, reuniendo a las personas sobre la base de la igualdad ${ }^{90}$.

Volviendo al epígrafe inicial que señala: "hablar es un movimiento en sí mismo y 'movimiento' conlleva dos sentidos básicos: movilidad corporal y organización política"91, entendemos que la acción colectiva emprendida por ANAMURI, en particular la llevada adelante en los Tribunales Éticos, constituye actos para colocar en lo público, involucrando a distintos agentes y actores de la sociedad civil y del Estado, la existencia de "cuerpos dañados" entre las trabajadoras de la agricultura de exportación. Al mismo tiempo, se trata de un modo de impartir justicia que cuestiona el monopolio de dicho concepto, toda vez

\footnotetext{
${ }^{89}$ Joe Foweraker y Ann L. Craig (eds.), Popular Movements and Political Change in Mexico, Londres y Boulder, Lynne Rienner, 1990.

90 Judith Butler, “'Nosotros el pueblo', Apuntes sobre la libertad de reunión”, en Varios Autores, ¿Qué es un pueblo?, Santiago, LOM, 2014, 41-59, 52.

${ }^{91}$ Ibid., 50.
} 
que el Estado, no necesariamente realiza esa labor en los casos denunciados. No obstante, la precariedad de la condición laboral de las temporeras, como organización social que las representa, ANAMURI afirma una identidad de género y clase estableciéndose como “contraloría laboral" frente al Estado y al empresariado. Aunque en parte enraizadas en el antiguo movimiento campesino de la década de 1960 por las demandas que plantean y las acciones que despliegan, sus miembros parecen, además de no negar la memoria del viejo movimiento campesino, abrir la esfera política, articular demandas populares y politizar asuntos previamente confinados al campo privado. Pero al mismo tiempo parecen también estar orientadas al fortalecimiento de la identidad colectiva como mujeres en el medio rural y la agricultura, y como plataforma para existir en el presente ${ }^{92}$.

Para concluir, hay dos aspectos que caracterizan el escenario en que se desenvuelve esta organización social que lucha por lograr el mejoramiento de las condiciones de trabajo de las temporeras. El primero es relevar la importancia que tiene una organización de nivel nacional para empujar y sostener a las organizaciones de nivel local y las luchas que en distintos lugares sostienen las mujeres por estos y otros aspectos relevantes en su vida cotidiana, por ejemplo, la escasez hídrica causada por la apropiación del agua por parte de las empresas. Esa pertenencia hace que los grupos locales tengan una identidad más allá de la pertenencia al lugar, que es refrendada en reuniones y congresos de ANAMURI. Lo segundo es la diversidad de su membrecía y su repartición a lo largo del país y la importancia que este aspecto tiene en la detección de otros problemas más allá de los derivados de las condiciones en que se realiza el trabajo asalariado, vinculados al extractivismo en zonas de pesca y a la violencia contra las comunidades indígenas en territorios de plantaciones forestales, entre muchos otros. Así, las mujeres se configuran como una "antena política" en el espacio rural que permite fortalecer la identidad de la organización, atenta a los problemas que generan las formas de trabajo y las formas de producción en el neoliberalismo, de la misma manera que esta otorga identidad colectiva al conjunto de sus asociadas. Así, el lugar que ocupa esta organización de mujeres en Chile frente a otro tipo de organizaciones y movimientos sociales $-\mathrm{O}$ populares- nos permite rescatar la idea de representación (hacia afuera) que las mujeres pueden lograr en un contexto de neoliberalismo y globalización, aunado a la idea de construcción de un actor social que se fortalece con el actuar colectivo, aunque muchas veces en luchas simbólicas con logros menguados.

De este modo, sus acciones se orientan al despliegue de tres estrategias en el campo político: la visibilización en el espacio público de las demandas de las mujeres en tanto trabajadoras agrícolas, productoras e indígenas; la interlocución con el Estado, y el fortalecimiento identitario tanto a nivel local, nacional e internacional. Los testimonios de sus miembros dan cuenta de la importancia de la organización para el "desarrollo político"

\footnotetext{
92 José Hernández, "Expresiones del debate de los Nuevos Movimientos Sociales en el contexto de Latinoamérica y México", El Cotidiano, 151, septiembre-octubre, México, Universidad Autónoma Metropolitana-Azcapotzalco, 2008, 5-20, 15; Alberto Melucci, Challenging Codes: Collective Action in the Information Age, Nueva York, Cambridge University Press, 1996.
} 
de las mujeres y como espacio de reconocimiento entre iguales ${ }^{93}$. De tal modo que a través de sus "formas de socialización han logrado construirse como sujetas políticas representadas [...] un espacio que las construye como mujer consciente de su propia realidad desde la historicidad y la clase trabajadora campesina"94.

En este marco, parece pertinente rescatar las ideas de Jacques Rancière. Formar parte de ANAMURI y de sus actividades y de la sociabilidad que se desarrolla en los espacios que sostiene a nivel nacional y también latinoamericano permite vivir el tiempo presente en tanto actor colectivo. Refiriéndose al concepto de emancipación, en alguna medida Rancière concuerda con ciertos aspectos esgrimidos por Butler: "La emancipación es de hecho una manera de vivir entre iguales en el mundo de la desigualdad, en lugar de esperar el reino de la igualdad prometida por el proceso global guiado por quienes conocen las formas de llegar a ello" 95 .

\section{Referencias}

\section{Fuentes impresas}

Aguayo, Carmen Gloria, Des chiliennes. Des femmes en lutte au Chili, París, Éditions Des Femmes, 1982.

Anríquez, Gustavo, et al., "Evidencia y desafíos para el empleo estacional en la fruticultura en Chile", Temas de la Agenda Pública, 11:85, Santiago, Facultad de Agronomía e Ingeniería Forestal, Pontificia Universidad Católica de Chile, enero, 2016, disponible en Internet: <www.politicaspublicas.uc.cl>.

Arendt, Hannah, Los orígenes del totalitarismo, Madrid, Taurus, 1998.

Arostegui, Julio, La Historia del Presente ¿Una cuestión de método?, Universidad Complutense de Madrid, Dialnet/laHistoriaDelPresente-1036594.pdf.

Auslander, Leora, y Michele Zacarini-Fournel, Différence des sexes et protection sociale, XIX et XX siècles, Saint-Denis, Presses Universitaires de Vincennes, 1995.

\footnotetext{
${ }^{93}$ Melany Cortés, Feminismo campesino y popular. Propuesta de un proyecto político en construcción, Tesis para optar al grado de Licenciada en Trabajo Social, Santiago, Universidad Academia de Humanismo Cristiano, 2015, 156.

${ }^{94}$ Ibid., 157.

${ }^{95}$ Jacques Rancière, “¿Quedó atrás el tiempo de la emancipación?”, Conferencia, Santiago, GAM, 2012. Existe una versión impresa de una conferencia sobre el mismo tema impartida en Bogotá, en el Museo Nacional de Colombia, también en 2012: Jacques Rancière, “¿Ha pasado el tiempo de la emancipación?”, Calle 14: Revista de investigación en el campo del arte, 9:13, mayo-agosto, Bogotá, Universidad Distrital Francisco José de Caldas, 14-27.
} 
Avendaño, Octavio, "Los partidos frente a la cuestión agraria en Chile, 1967-1973", Política, 52: 1, Santiago, Instituto de Asuntos Públicos, Universidad de Chile, 2014, 93-122.

Barraclouh, Solon, y Manuel Fernández, Diagnóstico de la Reforma Agraria chilena, México, Siglo XXI, 1974.

Barrón, Antonieta, Empleo en la agricultura de exportación en México, México, Juan Pablos, 1997.

Bendini, Mónica, y Nélida Bonaccorsi (comps.), Con las puras manos. Mujer y trabajo en regiones frutícolas de exportación, Buenos Aires, La Colmena, 1998.

Bengoa, José, Reforma agraria o revuelta campesina. Homenaje a los campesinos desaparecidos, Santiago, LOM, 2016.

LOM, 2015.

, Historia rural de Chile Central. Crisis y ruptura del poder hacendal, tomo II, Santiago, (ed.), Territorios rurales. Movimientos sociales y desarrollo territorial rural en América Latina, Santiago, RIMISP / Catalonia, 2007.

------------, “25 años de estudios rurales”, Revista Sociologías, 5:10, Porto Alegre, 2003, 36-98.

------------, Historia del movimiento campesino, Santiago, GIA, 1983.

Bock, Gisele, y Pat Thane (eds.), Maternidad y políticas de género. La mujer en los Estados de bienestar europeos, Valencia, Cátedra, 1991.

Boltanski, Luc, Yan Derré, Marie-Ange Schiltz. "La dennonciation", en Actes de la récherche en sciences sociales, Vol, 51, mars 1984, 3-40

Bourdieu, Pierre, Le bal des célibataires. Crise de la société paysanne en Béarn, París, Seuil, 2002.

Butler, Judith, “'Nosotros el pueblo', Apuntes sobre la libertad de reunión”, en Varios Autores, ¿Qué es un pueblo?, Santiago, LOM, 2014, 41-59.

Caro, Pamela, "El caso de Chile", en FAO / CEPAL / OIT, Empleo y condiciones de trabajo de mujeres temporeras agrícolas, tomo 1, Santiago, 2012, 143-221.

Castel, Robert, "Las transformaciones del trabajo en la sociedad capitalista actual", en Robert Castel en la Cátedra Unesco. Las transformaciones del trabajo, de la producción social y de los riesgos en un período de incertidumbre, Buenos Aires, Siglo XXI / Instituto Di Tella, 2010.

-----------, El ascenso de las incertidumbres. Trabajo, protecciones, estatuto del individuo, Buenos Aires, Fondo de Cultura Económica, 2010.

------------, La montée des incertitudes, París, Seuil, 2009.

------------, La inseguridad social. ¿Qué es estar protegido?, Buenos Aires, Manantial, 2004. 
Paidós, 1997.

, La metamorfosis de la cuestión social. Una crónica del salariado, Buenos Aires, Gabriel Kessler, Denis Merklen y Numa Mrard, Individuación, precariedad, inseguridad, Buenos Aires, Paidós, 2013.

Corrigan, Philip, y Derek Sayer, "El gran arco. La formación del Estado inglés como revolución cultural", en María Lagos y Pamela Calla (comps.), Antropología del Estado. Dominación y prácticas contestatarias en América Latina, La Paz, Cuadernos del Futuro, Informe sobre Desarrollo Humano, 2007, 40-16.

Cortés, Melany, Feminismo campesino y popular. Propuesta de un proyecto político en construcción, Tesis para optar al grado de Licenciada en Trabajo Social, Santiago, Universidad Academia de Humanismo Cristiano, 2015.

FAO / CEPAL / OIT, Empleo y condiciones de trabajo de mujeres temporeras agrícolas (Estudio de casos en 7 países), 2 tomos, Santiago, 2012.

Feder, Ernst, El imperialismo fresa. Un estudio sobre los mecanismos de dependencia de la agricultura mexicana, México, Editorial Campesina, 1977.

Foweraker, Joe, y Ann L. Craig (eds.), Popular Movements and Political Change in Mexico, Londres y Boulder, Lynne Rienner, 1990.

Fraisse, Geneviève, Los dos gobiernos: la familia y la ciudad, Madrid, Cátedra, 2013.

Fraser, Nancy, “¿De la redistribución al reconocimiento? Dilemas en torno a la justicia en una época 'postsocialista"', en Nancy Fraser, Iustitia Interrupta. Reflexiones críticas desde la posición “postsocialista”, cap. I, Bogotá, Siglo de Hombres, 1997, 17-54.

------------ y Axel Honneth, ¿Redistribución o reconocimiento?, Madrid, Morata, 2006.

Garret, Patricia, "La Reforma Agraria. Organización popular y participación de la mujer en Chile, 1964-1973”, en Magdalena León (ed.), Las trabajadoras del agro, Bogotá, ACEP, 1985.

Garza, Enrique de la, Reestructuración productiva y respuesta sindical en México, México, IIEUNAM / UAM-I, 1993.

Gaudichaud, Franck, Las fisuras del neoliberalismo chileno. Trabajo, crisis de la "democracia tutelada" y conflictos de clase, Santiago, Tiempo Robado, 2015.

Goody, Jack, La familia europea, Barcelona, Editorial Gráfica, 2002.

-------------, La evolución de la familia y el matrimonio en Europa, Barcelona, Herder, 1986.

Harvey, David, El “nuevo" imperialismo: acumulación por desposesión, Buenos Aires, CLACSO, 2005.

Harvey, Neil, La rebelión de Chiapas. La lucha por la tierra y la democracia, México, ERA. 
Hernández, José, "Expresiones del debate de los Nuevos Movimientos Sociales en el contexto de Latinoamérica y México", El Cotidiano, 151, septiembre-octubre, México, Universidad Autónoma Metropolitana-Azcapotzalco, 2008, 5-20.

Joinet, Louis, Mes raisons d'Etat. Mémoires d'un épris de justice, París, La Découverte, 2013.

Lara, Sara María, "Savoir gérer la distance et la précarité: les salariés agricoles au Mexique", Migrations Société, 153-154, mayo-agosto, 2014, 197-209.

-----------, "Los territorios migratorios como espacios de integración de las migraciones nacionales e internacionales. Cuatro estudios de caso en México", Política y Sociedad. Monográfico sobre migraciones, trabajo y cadenas globales, 49:1, septiembre, 2012, 89-102.

, "Movilidad y migración de familias jornaleras. Una mirada a través de genealogías", Empiria, UNED, Revista de Metodología en Ciencias Sociales, 19, enero-junio, 2010, 183-201.

y Hubert de Grammont, "Los efectos de las migraciones rurales internas en la conformación de los grupos domésticos", Mónica Bendini, Josefa Salete, Miguel Murmis y Pedro Tsakoumagkos (comps.), El campo en la sociología actual: una perspectiva latinoamericana, Buenos Aires, La Colmena, 2003, 213-236.

León, Magdalena, y Carmen Diana Deere, Género y derechos de las mujeres a la tierra en Chile, Santiago, CEDEM, 1999.

Melucci, Alberto, Challenging Codes: Collective Action in the Information Age, Nueva York, Cambridge University Press, 1996.

Mendoza, Angie, Incidencia del trabajo de temporada en familias migrantes nacionales y extranjeras. El Valle de Copiapó, Tesis de Magister, Santiago, Facultad de Ciencias Sociales, Escuela de Post-Grado, Universidad de Chile, 2011.

Murmis, Miguel, "Cuestión social y lazos sociales", en Mónica Bendini, Josefa Salete, Miguel Murmis y Pedro Tsakoumagkos (comps.), El campo en la sociología actual: una perspectiva latinoamericana, Buenos Aires, La Colmena, 2003, 53-76.

Neira, Paz, Trabajadores temporeros mapuche en la fruticultura: el caso de la Comunidad Juan José Ayenao, Tesis de Magíster, Santiago, Universidad Academia de Humanismo Cristiano, 2012.

Oszlak, Oscar, La trama oculta del poder. Reforma agraria y comportamiento político de los terratenientes chilenos, 1958-1973, Santiago, LOM, 2016.

Oxman, Verónica, "La participación social de las mujeres rurales", Santiago, GIA, 1983 (documento de trabajo).

Pedreño, Andrés, "La condición inmigrante del trabajo en las agriculturas globalizadas", Sara María Lara (coord.), Los "encadenamientos migratorios" en espacios de agricultura intensiva, México, El Colegio Mexiquense / Miguel Ángel Porrúa, 2011, 5-15.

Perrot, Michelle, Haciendo Historia en Género e Historia, comp. Carmen Ramos, México, Universidad Autónoma Metropolitana. 1992. 
Radonich, Marta, y Norma Steimbreger (comps.), Reestructuraciones sociales en cadenas agroalimentarias, Buenos Aires, La Colmena, 2007.

Ramírez, Pablo, Cambios en las formas de pago a la mano de obra agrícola, Santiago, ICIRA, 1968.

Rancière, Jacques, “¿Ha pasado el tiempo de la emancipación?”, Calle 14: Revista de investigación en el campo del arte, 9:13, mayo-agosto, Bogotá, Universidad Distrital Francisco José de Caldas, 2014, 14-27.

Rancière, Jacques, “¿Quedó atrás el tiempo de la emancipación?”, Conferencia, Santiago, GAM, 2012.

Rancière, Jacques, La Noche de los proletarios, Buenos Aires, Tinta Limón, 2010.

Rodríguez, Francisca, "Sembradoras del mañana, vital fuerza en la organización sindical", Agricultura y sociedad, 5:87, Santiago, GIA / Academia de Humanismo Cristiano, 1987, 64-72.

Rossemblat, Karen, "Por un hogar bien constituido. El Estado y su política familiar en los Frentes Populares”, en Lorena Godoy (ed.), Disciplina y desacato, Santiago, SUR / CEDEM, 1994.

Riquelme, Verónica, Más mujeres en los sindicatos. Sectores con alta sindicalización femenina, Santiago, Dirección del Trabajo, 2015.

Ruiz, Carlos, De nuevo la sociedad, Santiago, LOM, 2015.

Santana, Roberto, Agricultura chilena en el siglo XX: contextos, actores y espacios agrícolas, Santiago, Centro de Investigaciones Diego Barros Arana / DIBAM, 2016.

Slater, David, Nuevos movimientos sociales y el Estado en Latinoamérica, Ámsterdam, CEDLA, 1985.

Standing, Guy, Precariado, una carta de derechos, Madrid, Capitán Swing, 2014.

Tarrius, Alain, "Pobres en migración, globalización de las economías y debilitamiento de los modelos integradores en el transnacionalismo migratorio en Europa Meridional”, Empiria, UNED, Revista de Metodología en Ciencias Sociales, 19, enero-junio, 2010, 133-156.

Tinsman, Heidi, La tierra para el que la trabaja, Santiago, LOM, 2009.

Touraine, Alain, El retorno del actor, Buenos Aires, Editorial Universitaria, 1988.

Valdés, Teresa, "Centros de Madres ¿Sólo disciplinamiento?”, Santiago, FLACSO, 1989 (documento de trabajo, 416)

Valdés, Ximena, "Feminización del empleo y trabajo precario en las agriculturas latinoamericanas globalizadas", Cuadernos de Antropología Social, 41, Instituto de Ciencias Antropológicas, Sección de Antropología Social, Facultad de Filosofía y Letras, Universidad de Buenos Aires, 2015, 39-54.

Valdés, Ximena, "Trabajo agrícola temporal, familias, géneros", en Ximena Valdés et al., Trabajos y familias en el neoliberalismo. Hombres y mujeres en faenas de la uva, el salmón y el cobre, Santiago, LOM, 2014, 21-97. 
---------, “Conclusiones”, FAO / CEPAL / OIT, Empleo y condiciones de trabajo de mujeres temporeras agrícolas, Santiago, tomo I, 223-247, tomo II, 269-300, 2012.

, "Contra el desperdicio de la experiencia social: las temporeras y su acción colectiva", en Julio Pinto (ed.), Mujeres. Historias chilenas del siglo XX, Santiago, LOM, 2011, 117-140.

------------, La vida en común. Familia y vida privada en Chile y el medio rural en la segunda mitad del siglo XX, Santiago, LOM, 2007.

------------, “Campesinas”, en Sonia Montecino y Josefina Rossetti (eds.), Tramas para un nuevo destino. Propuestas de las mujeres de los partidos de la Concertación a la democracia, Santiago, Concertación de Mujeres por la Democracia, 1990.

, "Feminización del mercado de trabajo agrícola en Chile Central", Mundo de mujer. Continuidad y cambio, Santiago, CEM, 1988, 387-430.

------------, La posición de la mujer en la Hacienda, Santiago, CEM, 1988.

-----------, "Los procesos de incorporación y exclusión de las mujeres al mercado de trabajo agrícola”, en Ximena Valdés et al., Sinopsis de una realidad ocultada, Santiago, CEM, 1987, 2350 .

----------, "Hacia la generización de las trabajadoras del agro", Agricultura y sociedad, 5: 87, Santiago, GIA / Universidad Academia de Humanismo Cristiano, 1987, 27-49.

----------- y Carmen Gloria Godoy, "Mujeres de cuerpos dañados: las temporeras de la fruta en Chile", ponencia en GT 17, Antropología del trabajo y de los trabajadores/as. Intersecciones en los entramados del poder, VIII Jornadas de Investigación en Antropología Social Santiago Wallace (2729, julio, 2016, Buenos Aires, Argentina), Universidad de Buenos Aires, 2016.

-, Carmen Gloria Godoy, Ana López y Paula Raposo, "De la sindicalización campesina al estatuto del temporero. Pasado y presente en las luchas de los trabajadores agrícolas", Espacios, Revista de Geografía, 2:4, diciembre, Santiago, Universidad Academia de Humanismo Cristiano, 2012, 73-89.

\section{Documentos públicos y privados}

ENCLA 2014, Santiago, Dirección del Trabajo, Ministerio del Trabajo 2015.

INE. Censo Agrícola, ganadero y forestal 2007.

INDAP en cifras, primer semestre 2016, Población usuaria, Organizaciones de representación campesina, Santiago, INDAP, 2016.

INDAP, Programa PROGYSO, montos asignados a cada organización, 2016-

Mendoza, Angie, Sistematización Tribunales Éticos ANAMURI (documento interno FONDECYT), Santiago, 2016. 
SERNAM, Plan de Igualdad de Oportunidades para las Mujeres 1994-1999. Santiago, 1994.

SERNAM, Propuestas de Políticas de Igualdad de Oportunidades para las Mujeres Rurales. Santiago, 1997.

\section{Fuentes electrónicas o digitalizadas}

ANAMURI, página web: 〈www.anamuri.cl>.

Cuevas, Hernán, "Precariedad, precariado y precarización. Un comentario crítico desde América Latina a The Precariat. The New Dangerous Class de Guy Standing”, Revista Polis [en línea], 40, Santiago, CISPO / Universidad de los Lagos, 2015, publicado: 16 mayo 2015, consultado: 20 agosto 2015, disponible en Internet: 〈http://polis.revues.org/10754〉.

BíoBíoChile.cl, "Así vivían decenas de haitianos ilegales descubiertos en Longaví", 23 de noviembre de 2016, disponible en: <http://www.biobiochile.cl/noticias/nacional/region-delmaule/2016/11/23/revelan-las-precarias-condiciones-en-las-que-vivian-decenas-de-haitianos-enlongavi.shtml>.

The Clinic, "Los temporeros de Nepal que trabajan en Buin", 18 de diciembre de 2016, disponible en: 〈http://www.theclinic.cl/2016/12/18/los-temporeros-de-nepal-que-trabajan-en-buin/>.

\section{Referencias orales (entrevistas)}

Cortez, Julieta, dirigente social, socia ANAMURI, Canela Baja, entrevista enero 2016.

Grau, Patricia. Enfermera, Escuela Enfermeras, Universidad de Chile, entrevista noviembre 2016 Caro, Pamela, trabajadora social, investigadora, Doctora USACH / IDEA, asesora de ANAMURI, entrevista marzo 2016.

Muñoz, Alicia, dirigente ANAMURI, entrevista octubre 2015.

Opazo, Carlos, dirigente reforma agraria y miembro Ranquil, entrevista enero 2016.

Oróstica, Florencia, dirigente y socia ANAMURI Copiapó, entrevista agosto 2016.

Rodríguez, Francisca, dirigente nacional de ANAMURI, entrevista, agosto de 2015, enero 2016.

Sotomayor, Octavio, director de INDAP, entrevista, octubre de 2016.

Torres, Oscar, encargado de FEES 1967-1973, entrevista, 11 de octubre de 2016.

Willson, Angélica, antropóloga CEDEM, asesora ANAMURI, entrevista marzo 2016. 